\title{
The War on Poverty's Experiment in Public Medicine: Community Health Centers and the Mortality of Older Americans ${ }^{\dagger}$
}

\author{
Martha J. Bailey and \\ Department of Economics, University of Michigan, 611 Tappan Street, Ann Arbor, Michigan \\ 48109 \\ Andrew Goodman-Bacon \\ Department of Economics, University of Michigan, 611 Tappan Street, Ann Arbor, Michigan \\ 48109
}

Martha J. Bailey: baileymj@umich.edu; Andrew Goodman-Bacon: ajgb@umich.edu

\begin{abstract}
This paper uses the rollout of the first Community Health Centers (CHCs) to study the longer-term health effects of increasing access to primary care. Within ten years, $\mathrm{CHCs}$ are associated with a reduction in age-adjusted mortality rates of 2 percent among those 50 and older. The implied 7 to 13 percent decrease in one-year mortality risk among beneficiaries amounts to 20 to 40 percent of the 1966 poor/non-poor mortality gap for this age group. Large effects for those 65 and older suggest that increased access to primary care has longer-term benefits, even for populations with near universal health insurance. (JEL H75, I12, I13, I18, I32, I38, J14)
\end{abstract}

In 1965 US policymakers began a bold experiment in the provision of health care to the poor. Unlike the era's large public insurance expansions that subsidized the purchase of health care from private providers (Medicare and Medicaid), Community Health Centers (CHCs) used federal funds to deliver primary care to the poor and underserved populations. ${ }^{1}$ From the outset $\mathrm{CHCs}$ sought to increase the availability and convenience of care while reducing costs to patients. CHCs charged on a "pay as you can" sliding-scale for services and medications, were located in disadvantaged neighborhoods, and offered home visits and transportation to appointments.

The CHC model of primary care has survived for 50 years and has enjoyed a significant expansion in funding since 1995 (Figure 1). ${ }^{2}$ By 2008, more than 8,000 CHC sites operated in each of the 50 states and served over 20 million Americans, 40 percent of whom were uninsured and 70 percent of whom were poor (Adashi, Geiger, and Fine 2010). In 2010 the Affordable Care Act (ACA) appropriated an additional \$11 billion over five years to expand

\footnotetext{
${ }^{\dagger}$ Go to http://dx.doi.org/10.1257/aer.20120070 to visit the article page for additional materials and author disclosure statement(s). ${ }^{1}$ The earliest health centers were called "neighborhood health centers." Today CHCs include "Federally Qualified Health Centers" (FQHC) and so-called "Look-Alike FQHCs." We use "community health centers" in the paper to refer to all of these centers. 2 Between 2001 and 2007, the Federal Health Center Growth Initiative doubled health center funding from $\$ 1$ to $\$ 2$ billion (US DHHS 2008). The 2009 American Reinvestment and Recovery Act allocated funds to build 126 new facilities and expand 1,100 existing CHCs (Iglehart 2010).
} 
CHCs' infrastructure further to meet the primary care needs of the millions of Americans projected to gain health insurance under the ACA's provisions. Part of the rationale for this expansion relied on a widely held belief that CHCs improve access to primary care and curb increases in health care costs (Cunningham 2006; Falik et al. 2006; Rust et al. 2009;

Hawkins and Schwartz 2003).

Yet the limitations of existing studies caution against such strong causal claims. Not only have studies had difficulty identifying CHCs' effects on health care utilization, but few have measured their effects on health at all. Even if CHCs increase service use, they need not improve health or reduce health care costs if —as articulated by the program's early critics$\mathrm{CHC}$ services are lower quality than those available from private and non-profit providers (especially services covered by Medicare and Medicaid). ${ }^{3}$ If CHCs provide lower quality services that gradually erode health, they could ultimately worsen health and raise health care costs over the longer term.

This paper uses the rollout of CHCs from 1965 to 1974 to provide the first evidence of their long-term health effects and, more generally, the impact of increasing the availability of primary care to the poor. This historical vantage point allows us to evaluate CHCs' cumulative impact on health up to 15 years after they began operating, while using the "great administrative confusion" at the Office of Economic Opportunity (OEO) as our source of identifying variation (Levine 1970). Our main results show that the establishment of $\mathrm{CHCs}$ predicts sharp and persistent reductions in age-adjusted mortality rates. Within one decade of CHCs' establishment, age-adjusted mortality rates had declined by an additional 2 percent on average in treated counties. These reductions in mortality rates were driven by reductions in cardiovascular-related causes among adults ages 50 and older. We find little evidence that CHCs affected infant and child mortality rates.

Our rough translation of these intention-to-treat effects into effects on the treated implies that $\mathrm{CHCs}$ reduced mortality rates by 7 to 13 percent among the poor $50+$ year olds they treated-an effect equal to 20 to 40 percent of the 1966 poor/non-poor mortality gap for this age group. These results are robust to and often strengthened by standard sensitivity tests such as controlling for state-by-year fixed effects, county-level federal per capita medical spending, and linear county-level trends, as well as by reweighting areas without CHCs so that their observed characteristics resemble the distribution of those characteristics in areas with CHCs. Our placebo tests show that CHCs had no measurable impact on accidentrelated mortality in any specification, which is consistent with their provision of primary (but not emergency) care. We also find little evidence that the expansion of hospital capacity or other War on Poverty programs drive the results. Interestingly, large effects of CHCs on mortality rates occurred among those eligible for Medicare, but we find no accompanying increase in Medicare enrollment or spending.

\footnotetext{
${ }^{3}$ Early critics referred to the program as "a step toward socialism" (Sardell 1988, p. 61). Doctors feared competition from CHCs and expressed concerns about the quality of their care owing to their greater staffing with nurses and social workers and the development of practice guidelines by "lay persons" (Sardell 1988, p. 62). In 1966, the president of the American Medical Association (AMA) spoke against the program, arguing that the government's role in health care should be limited to "the overall stimulation and support of private enterprise, rather than under-taking specific operational or directional capacities" (Hudson 1966, p. 99).
} 
The body of evidence suggests that CHCs improved older-adult health in a variety of ways. Our analysis of the Survey of Health Services Utilization and Expenditures (SHSUE) highlights two important reasons for this. First, the share of older, poor adults in CHCserved locations who reported a "regular source of care" increased by 23 percent. Reporting a regular source of care is a stronger predictor of positive health outcomes than is having health insurance (Sox et al. 1998) and is also highly correlated with compliance with treatment for hypertension (Shea et al. 1992). Second, the SHSUE results suggest that the share of the older poor with out-of-pocket prescription drug expenditures fell by almost onethird in locations with CHCs (medications were highly subsidized or free at CHCs' in-house pharmacies). These findings - and the likelihood that reductions in mortality understate the broader health benefits of $\mathrm{CHCs}$ - highlight the value of interventions that increase access to primary care, even for populations with near universal health insurance coverage. Our analysis concludes with estimates of CHCs' costs per life-year, which are one-third to oneeighth of the size of the costs per life-year achieved by Medicare at the time of its implementation.

\section{History and Expected Effects of Community Health Centers}

In his first State of the Union Address in January 1964, President Lyndon Johnson declared an "unconditional war on poverty" (Johnson 1964). Central to his war was the 1964 Economic Opportunity Act (EOA), which aimed to "eliminate the paradox of poverty in the midst of plenty." The Office of Economic Opportunity (OEO) was created to administer the EOA initiatives and make direct grants to local organizations. ${ }^{4}$

Initially, the OEO focused on programs to promote human capital and community development like Head Start and Job Corps, but OEO administrators soon discovered that health problems and little access to care limited participation in their programs. Harrington's (1962, p. 15) iconic description of the era links poor health to the persistence of poverty:

The poor get sick more than anyone else in the society. That is because they live in slums, jammed together under unhygienic conditions; they have inadequate diets, and cannot get decent medical care. When they become sick, they are sick longer than any other group in the society. Because they are sick more often and longer than anyone else, they lose wages and work, and find it difficult to hold a steady job. And because of this, they cannot pay for good housing, for a nutritious diet, for doctors. At any given point in the circle, particularly when there is a major illness, their prospect is to move to an even lower level and to begin the cycle, round and round, toward even more suffering.

Compounding these problems was that few charity or reduced-cost providers existed in many parts of the United States during the 1950s and 1960s (Sardell 1988, p. 45). Doctor Raymond Wheeler, a member of the Citizen's Board of Inquiry into Hunger in the United States from 1967 to 1971, vividly described the limited access to medical care:

\footnotetext{
${ }^{4} \mathrm{OEO}$ funding was intended to ensure "the maximum feasible participation" of the poor and empower those who had been excluded from local politics to create positive changes in their communities. This direct-to-local-organization granting made the War on Poverty programs controversial because they challenged traditional political structures and entrenched local interests.
} 
We saw hundreds of people whose only hope of obtaining medical care was to become an emergency which could not be turned away. We heard countless stories of driving 50 or 100 miles to a city general hospital after refusal of care at a local hospital (1971, p. 2).

Even if an outpatient department existed locally, the "four-hour wait, multiple referrals, incredible discontinuity of care and various other indignities" (Knowles 1964, p. 733) deterred many from seeking services for non-emergency conditions.

To address the health needs of the poor, the OEO initiated the CHC program in 1965. The program aimed to deliver affordable, comprehensive care to disadvantaged populations. The initial wave of $\mathrm{CHC}$ grants established eight demonstration projects administered through medical schools, hospitals, and boards of health. The 1966 amendments to the EOA expanded funding through the OEO, and the 1967 Partnership for Health Amendments allocated additional funds for the Department of Health Education and Welfare (DHEW) to initiate CHCs (Davis and Schoen 1978, p. 163). By 1974 CHCs existed in 117 counties nationwide, with each site annually serving an average of 13,330 registered patients (Davis and Schoen, p. 178). Figure 1 shows that annual federal expenditures on CHCs reached around \$863 million (2012 dollars) in 1974 and fluctuated around this mean through 1990.

The OEO model allowed any organization to receive funding. Administrators reported receiving applications from "various and sundry groups" often having little to do with the legislation (Gillette 1996, p. 196, quoting Theodore M. Berry, assistant director of the $\mathrm{OEO}$ ). Awardees tended to be "one leading-edge, creative person who managed to get enough resources together ... pulling them [others at the organization] kicking and screaming into something that they really didn't want to be in, but that had lots of dollars attached to it" (May, Durham, and Kong-Ming 1980, p. 587). The first wave of CHC grants (1965-1974) reflects what often has been called the arbitrary funding process typical of the War on Poverty (Ludwig and Miller 2007; Bailey 2012; Bailey and Duquette 2014)—a claim we support quantitatively later in the paper.

The focus of the CHC program and its allocation of funding changed with the enactment of the 1975 Special Health Revenue Sharing Act. This Act mandated that funding for CHCs follow the Index of Medical Underservice (IMU), which also qualified underserved areas for HMOs, federal investments in health care professionals, and other federal health funding. 5 In practice, the 1975 Act also meant that grants were disproportionately awarded to rural and underdeveloped areas (Sardell 1983). By 1980, CHCs had started in another 497 countiestwo thirds of which were located in areas with fewer than 50,000 residents.

\section{A. What Did Community Health Centers Do and Whom Did They Serve?}

At their most basic level, CHCs provided low-cost primary medical care in poor communities. Data on their services in the first decade of the program are sparse, but one 1973 financial audit provides a snapshot (Davis and Schoen 1978, p. 187; reprinted in online

\footnotetext{
5 Initially constructed as part of the Health Maintenance Organization Act in 1973, the IMU was developed by the DHEW and the University of Wisconsin to identify areas of medical need. The IMU aggregates information on per capita primary medical care physicians, infant mortality rates, poverty rates, and the percentage of an area's population ages 65 or older.
} 
Appendix Table B1). Per registered patient (not all of whom sought care in a given year), CHCs provided medical care an average of 2.6 times per year and filled medical prescriptions an average of 2.5 times per year at in-house pharmacies. Laboratory tests were performed an average of 1.8 times, dental care was provided 0.6 times, and $\mathrm{X}$-rays were made 0.3 times per year. These services were either free or highly subsidized.

The CHC model distinguished itself by offering a range of auxiliary services as well. The OEO targeted "alternative" delivery strategies because administrators believed that existing providers (private physicians and crowded hospital out-patient departments) had discouraged the poor from seeking care. To improve outreach and communication, CHCs hired health center employees from the communities they served (Judd et al. 1976). To reduce wait and travel times, $\mathrm{CHCs}$ located in underserved neighborhoods and employed multiple clinics or mobile units. More than 90 percent provided home health care and transportation to appointments (Health Services Administration 1974, p. 60). ${ }^{6}$

If CHCs meaningfully reduced the costs of receiving primary care, they should have (weakly) increased the use of primary care on both the extensive and intensive margins. Moreover, this effect should be largest among those least able to travel or afford care (those without insurance, for instance). We have found only one nationally representative data source that allows us to test this claim. The SHSUE covers the period before and after the CHC program began (1963 and 1970) and asks respondents to describe their use of "clinics" (including CHCs) (Center for Health Administration Studies/National Opinion Research Center 1981, 1988). Because the SHSUE sampled the same primary sampling units (PSUs) in both periods, we use a differences-in-differences (DD) estimator to compare changes in outcomes in 17 of the PSUs with CHCs to changes in outcomes in the 56 PSUs that did not get them by 1970 .

We find that the use of a "clinic" as the regular source of care (no regular source of care is coded as a zero) almost doubled, increasing by 8 percentage points more (s.e. 0.03) in areas that received a $\mathrm{CHC}$ before 1970 relative to a baseline of 9 percentage points. Consistent with $\mathrm{CHCs}$ disproportionately serving the poor, this estimate is almost twice as large among poor households (14 percentage points, s.e. 0.05 ) relative to households with incomes above 300 percent of the poverty line. ${ }^{7}$ Furthermore, the SHSUE data show small and insignificant changes in clinic use in nonurban areas receiving $\mathrm{CHCs}(0.05$, s.e. 0.04$)$, but a substantial increase in urban areas $(0.09$, s.e. 0.03$)$.

\section{B. Trends in Mortality Rates}

Our analysis follows the literature on health in the 1960s and uses mortality rates to proxy for health status. Although mortality is a limited measure of health, it is reliably and

\footnotetext{
${ }^{6}$ The 1972 Directory of CHCs (DHEW 1972a, b), for instance, reports that the CHC program in Denver, Colorado, had two health centers, 11 satellite health "stations," a staff of over 800 members, and was supposed to serve a population of 287,869 (almost 106,000 patients were enrolled in 1971). The CHC program in Oakland, California, provided comprehensive ambulatory care 24 hours per day, employed 52 physicians, and aimed to serve a population of 40,000 (17,289 were enrolled in 1971).

${ }^{7}$ Online Appendix A provides a description of the SHSUE and online Appendix Table F6 presents these results in table format.

Covariates include indicators for single ages (5-year groups above age 80), race, PSUs, a dummy variable for observation in 1970, and an interaction of whether the PSU had a CHC by 1970 and the 1970 dummy. Reported DD estimates refer to the coefficient on the interaction. Estimates for lower- and higher-income families come from separate regressions on samples by poverty status.
} 
consistently measured for our period of interest. We compute mortality rates using the 1959 to 1988 Vital Statistics Multiple-Cause of Death Files (US DHHS and NCHS 2007), which contain the universe of civilian deaths reported by cause, age, and the decedent's county of residence. We combine the mortality data with county population and birth data to create infant mortality rates as well as age-specific and age-adjusted mortality rates (AMR), which we disaggregate into six leading causes of death: (i) diseases of the heart, (ii) other cardiovasculardiseases (mainly cerebrovascular causes like strokes), (iii) cancer, (iv) infectious disease, (v) diabetes, and (vi) accidents (see online Appendix A for details on coding and online Appendix $\mathrm{C}$ for trends by cause).

Figure 2 describes our data and also shows that the CHC program rolled out during a period of dramatic declines in US mortality rates. The US AMR fell by around 29 percent from 1960 to 1988, which reflected improvements in all age groups. For infants, children (ages 1 to 19), adults (ages 20 to 49), and older adults (ages 50+), mortality rates fell by 62, 49, 22, and 28 percent, respectively. The causes of these declines in mortality rates reflect different factors for different groups - only some of which may be related to the availability of CHCs.

Large declines in infant mortality were driven by improvements in infant survival conditional on fitness at birth (Lee et al. 1980). ${ }^{8}$ In the 1960s, improved access to medical care resulting from the desegregation of hospitals and the initiation and expansion of Medicaid significantly reduced infant mortality (Almond, Chay and Greenstone 2006; Goodman-Bacon 2013; Currie and Gruber 1996b). During the 1980s, acute neonatal care (neonatal intensive care units) helped less healthy infants survive. Improvements in access to medical care also reduced the mortality of older children, especially mortality due to common childhood diseases such as pneumonia and meningitis, which together accounted for 11 percent of all childhood deaths in 1965. Medicaid coverage also played an important role for poor children as it increased access to medical care for conditions easily treatable with antibiotics (Goodman-Bacon 2013; Currie and Gruber 1996a). Finally, reductions in accident-related deaths - which accounted for 40 percent of childhood deaths in 1965played an important role in reducing child mortality in the 1960s and 1970s, reflecting in large part greater seat belt use and lower speed limits.

The reduction in older adult mortality (ages 50+) accounted for 75 percent of the aggregate decline in mortality rates from 1960 to 1988 . The most important proximate factor was the reduction in deaths due to major cardiovascular causes (CVD, causes 1 and 2 above). Over the period of interest, Goldman and Cook (1984) find that roughly half of the decline in ischemic heart disease was due to changes in lifestyle (cholesterol reduction and smoking cessation) and half was due to improved medical treatment. Innovations in medical treatment included the inpatient treatment of acute cardiovascular incidents (including drugs to dissolve blood clots, bypass surgery, and angioplasty, Cutler and Meara 2001) and the development of medications to manage hypertension on an outpatient basis (Long et al. 2006).

\footnotetext{
${ }^{8}$ Although fitness at birth improved over the period with the growth in nutritional support for young children and mothers through the Food Stamps and the Women, Infants and Children programs, these programs contributed to improvements in birth weight more than infant survival (Almond, Hoynes, and Schanzenbach 2011; Hoynes, Page, and Stevens 2011).
} 
Anti-hypertensive drugs, including diuretics and vasodilators, are believed to be among the most important contributors to the reduced mortality rates for adults 50 and older because they prevented potentially fatal incidents for a relatively low cost (Crimmins 1981, p. 244; Freis 1995; Cutler and Kadiyala 2003). After randomized trials by the Veterans Administration Cooperative Group (VACG in the late 1960s demonstrated these drugs' effectiveness, the National Institutes of Health launched a campaign to promote awareness of hypertension. People were encouraged to "know your [blood pressure] number," and physicians were encouraged to screen and treat the disease. ${ }^{9}$

\section{The Expected Effects of Community Health Centers on Mortality Rates}

The expected effects of CHCs on mortality rates depends both on the incidence of causes CHCs might prevent and the effectiveness of CHCs' care relative to alternatives. For infants and children, for instance, deaths are relatively rare (less than 9 percent of all deaths over the 1959-1988 period were to individuals under age 15), and fewer could have been prevented with primary care. Approximately 41 percent of child deaths due to "external causes" (accidents, homicides, suicides, etc.) were unlikely to be affected by CHCs. And although infant mortality rates (mostly due to internal causes) were high, CHCs' primary and preventative care may not have increased survival. CHCs could have helped parents get an earlier diagnosis of potentially lethal diseases and afford medications for treatment, but they were not substitutes for hospitals' acute care for sick infants. In short, we do not expect $\mathrm{CHCs}$ to have large effects on infant and child mortality.

The overwhelming number of deaths that CHCs could have prevented occurred among adults ages 50 and older. This group not only comprised a large share of US deaths (80 to 88 percent from 1960 to 1988), but many of these deaths would have been responsive to the provision of primary care. In this regard, CHCs could have reduced mortality rates by increasing early detection of health problems, by providing free or highly subsidized medications to treat conditions (not covered by Medicare or Medicaid in most cases, Finkelstein and McKnight 2008; Davis and Schoen 1978, p. 55), and by increasing awareness about Medicare (Chay, Kim, and Swaminathan 2011) and Medicaid, both of which could increase access to life-saving hospital treatments. Similarly, CHCs' outreach and follow-up efforts could have had important effects on the management of common, fatal, chronic conditions like hypertension that required consistent and long-term use of medication. Finally, CHCs may have reduced the mortality of community members who did not use CHCs' services by reducing emergency room crowding, lowering the incidence of infectious disease, and spreading health information. For all of these reasons, we expect CHCs to have large effects on the mortality rates of older adults.

\footnotetext{
${ }^{9}$ The first VACG study randomly assigned 73 middle-aged men with moderate hypertension (diastolic blood pressure between 115 and $129 \mathrm{~mm} \mathrm{Hg}$ ) to a treatment group that received three hypertension medications. Seventy-three men were also assigned to a control group that received placebo medications. The control group experienced 27 morbid events and four deaths while the treatment group experienced only two morbid events and zero deaths (VACG 1967). Researchers terminated the study for moderate hypertensives after six months due to the large observed treatment effects. The second VACG study used the same methodology but focused on 380 men with low hypertension (diastolic blood pressure between 90 and $114 \mathrm{~mm} \mathrm{Hg}$ ). The study followed patients for an average of 3.3 years during which time 21 control patients and ten treatment patients died. In addition, more than twice as many control patients had assessable morbid events (VACG 1970). During the 1970s and 1980s, the share of hypertensives who learned their blood pressure number increased from 50 to over 70 percent and the share taking anti-hypertensive medication increased from 35 to over 55 percent (Cutler and Kadiyala 2003, figures 12 and 13).
} 
Offsetting these potential gains, however, CHCs may have reduced the quality of care. Although many accounts suggest that $\mathrm{CHCs}$ provided higher quality care than did hospital outpatient departments, physicians raised concerns over the use of nurses and social workers in CHCs and the development of practice guidelines by "lay persons" (Sardell 1988, p. 62). This is especially relevant in our period of study as alternative sources of care were private providers whose services may have been covered under Medicaid or Medicare. If CHCs provided lower quality care than these private alternatives, then CHCs' diversion of care from higher quality sources could have increased mortality rates. This possibility makes the overall sign of CHCs' effects on mortality rates as well as their quantitative importance theoretically ambiguous.

\section{Previous Studies of the Effects of Community Health Centers}

A large body of research has examined CHCs, but reliance on empirical methodologies with limited internal validity cautions against drawing strong causal inferences from their results. ${ }^{10}$ The frequent use of cross-sectional variation is tenuous because communities with CHCs differ in a number of observable ways from counties without CHCs. Table 1 shows that counties receiving CHCs (what we call "treated" counties) tended to be more urban, to be more affluent (greater share of households with incomes above $\$ 10,000$ ), to have lower poverty rates (smaller share of households with incomes below $\$ 3,000$, the 1960 poverty line for a family of four), to have more nonwhites per population, and to have more active physicians per capita. They also tended to have medical schools. This may seem contrary to the program's mission of reaching the underserved, but it is consistent with local advocates submitting grant proposals on behalf of needier residents-more affluent urban areas were best situated to do this.

More recent studies of CHCs use panel data to account for these cross-sectional differences using fixed effects. In one of the earliest studies of this type, Goldman and Grossman (1988), who examine infant mortality rates in the 678 largest counties between 1970 and 1978, find that an increase in the number of CHCs is associated with an overall reduction in infant mortality rates, particularly among blacks (see also Shi et al. 2003 and O'Malley et al. 2005). Using a 1996 to 2006 county panel and a specification with clinic and year fixed effects, Lo Sasso and Byck (2010) provide the best evidence to date that increases in CHC funding raise service availability and staffing while reducing uncompensated care. It is possible, however, that their results reflect omitted variables that affect both CHC performance and administrator decisions. For instance, their results could capture administrator decisions to defund poorly performing $\mathrm{CHCs}$ or increase $\mathrm{CHC}$ funding as part of a community development effort, both of which could lead their empirical strategy to overstate the effects of CHCs. On the other hand, if administrators increased funding to help

\footnotetext{
${ }^{10}$ Much of the literature examines a single $\mathrm{CHC}$ or a narrow geographic area and therefore cannot separate the effects of CHCs from changes in local policies or circumstances. For examples of case studies, see Bellin, Geiger, and Gibson (1969) and Moore, Bernstein and Bonanno (1972) on Boston; Chabot (1971) on Denver; Hochheiser, Woodward, and Charney (1971) on Rochester; Gordis (1973) on Baltimore; and O'Connor, Wagner, and Strogatz (1990) on an unspecified area in rural North Carolina. Two studies compare outcomes in five cities (Okada and Wan 1980; Freeman, Kiecolt, and Allen 1982). Focusing on later periods, Deprez, Pennell, and Libby (1987) use data from 36 CHCs in Maine in 1980, Ulmer et al. (2000) study medical records from 20 clinics across 10 states, and Epstein (2001) focuses on clinics in Virginia only. In studies of CHCs' effects on diabetes, Chin et al. (2000) examine 55 Midwestern cities and Bell et al. (2001) study 14 clinics in North Carolina.
} 
failing CHCs or to respond to declining local investments in community health, their estimates could understate the effects of $\mathrm{CHC}$ funding. To avoid both sources of endogeneity, we rely on variation in when and where CHCs were established rather than changes in funding - a decision we discuss in more detail in the next section.

Another limitation of the literature is that few studies consider the health effects of CHCs. The handful that do focus on infants (Chabot 1971; Goldman and Grossman 1988; Shi, Macinko, Starfield, et al. 2004; and Shi, Stevens, Wulu, et al. 2004) or specific health conditions (Gordis 1973 for rheumatic fever; Dignan, Hall, and Hastings 1979 for cardiovascular disease; Hicks et al. 2006 for asthma; Chin et al. 2000 and Hicks et al. 2006 for diabetes; O'Connor, Wagner, and Strogatz 1990 and Hicks et al. 2006 for hypertension; Hedberg et al. 1996). Our analysis is the first to consider the longer-term impacts of CHCs on mortality rates as well as to characterize heterogeneity in these effects by age group, race, and population density.

\section{Data and Research Design: Using the Rollout of Community Health Centers to Quantify Their Mortality Effects}

Newly compiled data on when and where CHCs were established facilitate this paper's research design. The following sections describe our data on CHCs, present empirical evidence motivating our research design, and discuss our empirical specifications.

\section{A. Data on Health Centers and County-Level Mortality Rates}

We use two data sources to document the rollout of CHCs from 1965 to 1974: the National Archives Community Action Program (NACAP) electronic files and hand-entered annual Public Health Service Reports. Both are verified using primary sources (US Congress 1967; OEO 1967, 1968; DHEW 1972a, 1972b; Zwick 1972; GAO 1973; Health Services

Administration 1974; Judd et al. 1976). Our amalgamated dataset contains information on (i) the county where CHCs delivered services, which allows each federal grant to be linked to county-level mortality rates, and (ii) the date when each county received its first $\mathrm{CHC}$ services grant (this excludes planning grants), which provides a consistent proxy for the year each CHC became operational — what we refer to as the "establishment date."

Our robustness checks use supplemental data on CHC grants between 1975 and 1980 from the National Archives Federal Outlays files (NAFO) and other primary sources. These data allow us to identify 497 largely rural CHCs begun in this later period. The lack of exact start dates for many of these $\mathrm{CHCs}$, the dependency of qualification for $\mathrm{CHC}$ funding on the Index of Medical Underservice (leading to the packaging of new CHCs with other health services), and the limited data on the implicit first stage lead us to focus our discussion on estimates that rely solely on CHCs established between 1965 and 1974. (Online Appendix A contains details about the data and source material and online Appendix $\mathrm{H}$ contains results using all CHCs begun before 1981 for interested readers).

Figure 3 maps the rollout of the CHC program between 1965 and 1980 by the year range and the county of establishment, the smallest area consistently identified over our period of interest in the mortality files. Counties with CHCs established in fiscal years 1965 to 1974 
are shaded. The first CHCs in Columbia Point (Boston), Massachusetts, and Mound Bayou, Mississippi, were established in fiscal year 1965 in collaboration with Tufts Medical School. As the CHC program expanded between 1965 and 1974, it achieved broad geographic coverage. All US regions had CHCs: 48 were established in the South, 21 in the Northeast, 22 in the Midwest, and 26 in the West. There is also considerable within-state variation in CHC establishment dates.

\section{B. Event-Study Specification}

Our empirical strategy uses variation in when and where $\mathrm{CHC}$ programs were established to quantify their effects on mortality rates. The findings from two empirical tests support a key assumption of this approach - that the timing of $\mathrm{CHC}$ establishment is uncorrelated with other determinants of changes in mortality. First, most 1960 socio-demographic characteristics of counties receiving a $\mathrm{CHC}$ in our period of interest in Table 1 fail to predict when a CHC was established (online Appendix Table D1). ${ }^{11}$ Significant exceptions are urban share and share of physicians (MDs) per county population. This is not surprising because larger, denser places had more resources and organizations that could apply for funding. Also, CHCs were set up in locations with physicians to staff them. To account for these potential threats to internal validity, we include urban-group-by-year fixed effects and linear trends interacted with the number of physicians in 1960 in addition to county fixed effects in our primary specifications.

Second, we examine whether CHC establishment timing is correlated with levels or trends in pre-program AMR. This could be the case if, for instance, proposals originated sooner in locations with higher mortality rates or the OEO prioritized locations using mortality rates or their correlates. Figure 4, which plots the AMR in 1965 and changes in the AMR from 1960 to 1965 against the year of $\mathrm{CHC}$ establishment in treated communities, shows no evidence of either scenario (see online Appendix Figure D1 for results by age group). The establishment of CHCs is uncorrelated with pre-existing levels and changes in AMR in either univariate or multivariate regressions. The lack of a systematic correlation between $\mathrm{CHC}$ establishment and most socio-demographic characteristics or mortality rates is consistent with the oral history's characterization of a "wild" funding process at the OEO. After presenting the empirical strategy and results, the last section of the paper returns to these concerns and provides further tests for specific threats to the internal validity of the research design.

Our empirical strategy exploits variation in the location of CHCs and the timing of their establishment within a flexible event-study framework (Jacobson, LaLonde, and Sullivan 1993),

\footnotetext{
${ }^{11} \mathrm{We}$ chose these characteristics because they have been shown to predict the timing of the implementation of other War on Poverty programs. Almond, Chay, and Greenstone (2006) and Hoynes and Schanzenbach (2009) report statistically significant relationships between these characteristics and both the timing of Medicare certification and the initiation of the Food Stamps program. The power of our study relative to Hoynes and Schanzenbach is limited in that we do not have information on the month of program initiation and that not all of the counties in the United States received CHCs.
} 


$$
\begin{gathered}
Y_{j t}=\theta_{j}+\gamma_{u(j) t}+\delta_{s(j) t}+\mathbf{X}_{j t}^{\prime} \boldsymbol{\beta}+\sum_{y=-7}^{-2} \pi_{y} D_{j} 1\left(t-T_{j}^{*}=y\right) \\
+\sum_{y=0}^{15} \tau_{y} D_{j} 1\left(t-T_{j}^{*}=y\right)+\varepsilon_{j t} .
\end{gathered}
$$

Here $Y_{j t}$ is a mortality outcome in county $j$ in year $t=1959, \ldots, 1988 .{ }^{12} \theta_{j}$ is a set of county fixed effects, which absorbs time-invariant differences in observable (Table 1) and unobservable characteristics and allows consistent estimation of $\pi$ and $\tau$ even in the presence of differences between treated and untreated locations. $\gamma_{u(j) t}$ is a set of urban-group-by-year fixed effects. ${ }^{13} \delta_{s(j) t}$ is a set of either year fixed effects or state-by-year fixed effects, which captures time-varying national changes such as Medicare or state-level implementation of Medicaid and the Civil Rights Act (Almond, Chay, and Greenstone 2006). $\mathbf{X}_{j t}$ includes a constant, the interaction of 1960 characteristics with linear time trends (share of population: in urban area, in rural area, under 5 years of age, 65 or older, nonwhite, with 12 or more years of education, with less than 4 years of education, in households with income less than $\$ 3,000$, in households with incomes greater than $\$ 10,000$, total active MDs), and annual county-level per capita measures of government transfers from the Bureau of Economic Analysis Regional Information System (REIS), which includes cash public assistance benefits such as Aid to Families with Dependent Children, Supplemental Security Income, and General Assistance; medical spending such as Medicare, Medicaid, and military health care; and cash retirement and disability payments. ${ }^{14}$

We use a binary indicator of treatment, $D_{j}$, equal to 1 if the county ever received a CHC grant. This captures "treatment" with a CHC. A practical reason for the choice of a binary treatment variable is that the NACAP data are missing grant amounts for 1969, which we have not been able to recover from other sources. The substantive reason is that larger per capita grants tended to support greater infrastructure development rather than a larger "dose" of CHC services. ${ }^{15}$ The estimates characterizing the effects of CHCs are, therefore, the coefficients on the interaction of $D_{j}$ with event-year dummies, $1\left(t-T_{j}^{*}=y\right)$, which are equal to 1 when the year of observation is $y=-7, \ldots, 0, \ldots, 15$ years from $T_{j}^{*}$, the date when a CHC was received in county $j(y=-1$ is omitted). Observations more than 6 years before or more than 14 years after $\mathrm{CHC}$ establishment are captured by dummies, $1\left(t-T_{j}^{*} \leq-7\right)$ and $1\left(t-T_{j}^{*} \geq 15\right)$. The point estimates, $\pi_{y}$, describe the evolution of mortality in eventually

\footnotetext{
12 Because models are weighted by the relevant 1960 population to account for heteroskedasticity by population size, we exclude New York, Los Angeles, and Chicago from our sample. These places had two million more residents in 1960 than the next largest counties and would receive disproportionate weight in our regressions. We also eliminate 18 counties with missing data. These sample restrictions leave us 3,044 counties in our primary sample.

${ }^{13}$ These are defined as year dummies interacted with five categories of a county's population share in urban areas, $u$ : $0,0<u<25,25$ $\leq u<50,50 \leq u<75,75 \leq u \leq 100$. This captures the differential diffusion of medical technologies and changes in health in areas with varying levels of urbanization.

${ }^{14}$ For the purposes of this analysis these covariates are fairly comprehensive because OEO administrators would have had limited information beyond them. The county characteristics in $\mathbf{X}$ are comparable to specifications in Almond, Hoynes, and Schanzenbach (2011) except that we also add information on the number of physicians per capita.

${ }^{15}$ This claim is consistent with historical reports and our empirical findings. Our analysis of heterogeneity in effects by above- or below-median per capita first CHC grants (for CHCs not funded in 1969) shows that substantial differences in funding (\$7 versus $\$ 45$ dollars per capita, 2012 dollars) reduced mortality rates by statistically indistinguishable amounts. Results using cumulative dollars are reported in online Appendix Table G3 for the interested reader.
} 
treated counties before $\mathrm{CHCs}$ began net of changes in untreated counties after adjusting for model covariates. They allow a direct evaluation of the assumption that the location and timing of $\mathrm{CHCs}$ is unrelated to pre-program changes in mortality. $\tau_{y}$ describes the divergence in outcomes $y$ years after the $\mathrm{CHC}$ was established net of changes in untreated counties after adjusting for model covariates. These estimates are intention-to-treat effects of CHCs on mortality relative to the year before CHCs began $(y=-1)$.

We summarize the magnitudes and joint statistical significance of the event-study estimates in a DD's specification that replaces the individual event-year dummies, $1\left(t-T_{j}^{*}=y\right)$, with year groups, $D_{j}^{g}$ where $D_{j}^{g}$ is a binary variable equal to 1 if county $j$ is observed in eventyear group $g$, where $g$ is a category for $y \leq-7,-6 \leq y \leq-2,0 \leq y \leq 4,5 \leq y \leq 9,10 \leq y \leq 14$, and $y \geq 15$ ( $y=-1$ is omitted). For both the event-study and DD specifications, tables and figures present only coefficients estimated using a balanced set of counties (only eventyears -6 to 14). To explore the sensitivity of our results, we add covariates sequentially; estimate models with county-specific, linear time trends $\left(\theta_{j} t\right)$ rather than parameterizing county trends using Table 1 characteristics; and reweight the untreated counties using a function of the estimated propensity of receiving a $\mathrm{CHC}$ to balance the characteristics of treated and untreated counties in Table 1 (DiNardo, Fortin, and Lemieux 1996; Heckman et al. 1998). ${ }^{16}$ Standard errors are corrected for an arbitrary within-county covariance structure (Arellano 1987).

\section{Estimates of the Relationship between Community Health Centers and Mortality}

The results presented in this section suggest that $\mathrm{CHCs}$ dramatically reduced mortality rates. The analysis begins by examining the effects of CHCs on age-adjusted mortality rates aggregated over all age groups and causes. To shed light on the possible mechanisms for these effects, we examine the relationship of CHCs with mortality rates in different age groups and with mortality attributable to different causes.

\section{A. Results for All-Cause, Age-Adjusted Mortality Rates}

We summarize the effect of CHCs in treated locations using the age-adjusted mortality rates for all ages and causes. Figure 5 plots weighted, event-study estimates from our baseline specification that includes state-by-year fixed effects, $\delta_{s(j) t}$, and county-level covariates, $\mathbf{X}_{j t}$. The series plotted with circles presents results for 1959-1988 and defines treatment using all CHCs begun between 1965 and 1980. The thick-line series presents results from the same sample and defines treatment using only the early CHCs (1965-1974), and the dashed lines show 95 percent confidence intervals for this series. The triangle series presents results for the early CHCs on a sample that uses the 388 counties with geographic identifiers through 1998.

\footnotetext{
${ }^{16}$ See online Appendix Figures D3 and D4 and online Appendix Table D4 for complete details on how we construct the propensity scores and descriptive statistics on the distribution of propensity scores in treated and untreated counties.
} 
The results are similar in the three cases and provide no evidence of a differential trend in mortality in treated locations before $\mathrm{CHC}$ programs began. This implies that the econometric model captures the wide-spread declines in the AMR in the years prior to $\mathrm{CHC}$ establishment (urban-by-year effects are plotted in online Appendix Figure D2). The estimates of the pre-CHC $(\pi)$ are small in magnitude and statistically indistinguishable from zero. Following the establishment of CHCs, mortality rates fell sharply. In the first five years after the early CHCs began (years 0 to 4 ), the AMR was 10 deaths lower per 100,000 in the baseline specification for treated locations - a reduction of 1.1 percent over a baseline AMR of 929 deaths per 100,000 (Table 2, column 2). In years 5 to 9 after these CHCs began, the AMR was 2 percent lower per 100,000 in treated locations (Table 2, column 2).

Post-CHC declines in mortality rates are not as sharp for the later centers (those funded between 1975 and 1980) as for the earlier centers (1965-1974), although these differences are not statistically significant. ${ }^{17}$ One potential reason for this is that legislation in 1975 substantially changed the selection of new $\mathrm{CHC}$ sites to favor more rural areas (Table 1). Sardell (1988, p. 112) explains that rural programs were "smaller than the first neighborhood health centers. Because rural areas, especially isolated ones, had a 'paucity of critical resources' and limited technical expertise and management capacity, bureau officials believed it necessary to establish programs on a much smaller scale than in the past." Rural $\mathrm{CHCs}$ struggled to reach their highly dispersed target populations in multiple counties. They were much less convenient than their urban counterparts, and low population density limited spill-overs and externalities. Consistent with this history, Section IA shows that more rural areas did not experience statistically significant increases in clinic use after CHCs began. Given this history and these results on use, it is not surprising that Figure 6 shows that the mortality effects of the early $\mathrm{CHCs}$ are much more pronounced for more urban areas than for rural areas (see online Appendix $\mathrm{H}$ for results for all $\mathrm{CHCs}$ ). In unreported results, we find that the effects of CHCs were almost six times larger in more urban counties 5 to 9 years after the $\mathrm{CHC}$ began and more than seven times as large in years 10 to 14 -estimates statistically different at the 5 and 11 percent levels, respectively.

The longer 1959 to 1998 sample sheds light on the persistence of CHCs' effects for the 388 counties (of the 3,044 counties in our primary analysis) that were large enough to be individually identified in the mortality data through 1998. In fact, this sample restriction has little effect on the estimates. During the additional ten years (event years 15 to 24) for which we can estimate CHCs' effects, mortality rates remain significantly lower than those before CHCs began. It appears that $\mathrm{CHCs}$ ' treatment effects outlasted both the initial enthusiasm of War on Poverty advocates and the subsequent (multiple) administrative changes in the program. This persistence suggests CHCs provided long-run, cumulative benefits to communities evident as much as 25 years after they began.

Panel A of Table 2 examines the robustness of these estimates by adding county fixed effects, $\theta_{j}$, and urban-group-by-year fixed effects, $\gamma_{u(j) t}($ column 1); then state-by-year fixed

\footnotetext{
${ }^{17}$ The trend break in mortality rates for both groups of CHCs at $t=0$ is apparent and economically and statistically significant. However, estimates for all CHCs are smaller at year 9. Misclassification error in establishment dates of later CHCs (due to data limitations described previously) likely induce measurement error and attenuation bias.
} 
effects, $\delta_{s(j) t}$, and county-level covariates, $\mathbf{X}_{j t}$ (column 2, our baseline specification); and finally county-specific linear trends rather than covariates interacted with linear trends (column 3). A final specification reweights the comparison group using the inverse propensity scores of receiving a CHC (column 4, see online Appendix Table D5 for trimmed estimates, as suggested by Crump et al. 2009). Across specifications, the magnitudes and standard errors are similar. The addition of over 3,000 county-specific linear trends in column 3 alters the estimates by 1 death per 100,000 in years 0 to 4 , by about 3 deaths per 100,000 in years 5 to 9 , and by 6 deaths in years 10 to 14 . Inverse propensity score reweighting, has similarly small effects on the estimated magnitudes. Neither set of estimates (columns 3 or 4), however, are statistically distinguishable from our baseline specification (column 2).

The robustness of the estimates in the reweighted sample is particularly helpful in narrowing the scope of omitted variables bias, because the reweighted sample has a slightly larger number of physicians per capita and is slightly more likely to have a medical school (though neither difference is statistically significant, Table 1, columns 7 and 8). This is inconsistent with the argument that the diffusion of hospital treatments (such as the development of bypass surgery in 1968) disproportionately affected CHC locations relative to the reweighted counterfactual group. ${ }^{18}$ Overall, the results imply that within 10 years, CHCs reduced age-adjusted mortality rates by around 2 percent in treated counties.

\section{B. The Relationship between CHCs and Mortality by Age Group}

CHCs' population-level effects reflect large changes in the mortality of individuals 50 or older because they comprise the majority of deaths in the population. Figure 7 disaggregates CHCs' effects by four age groups. As expected, the pattern for older adults using our baseline model (Figure 7, panel D) is similar to the population-level estimates: $\mathrm{CHCs}$ are associated with a 2.2 percent reduction in age-adjusted mortality rates of older adults (see Table 2, panel B for alternative specifications). ${ }^{19}$ The relationship between CHCs and mortality rates of other age-groups, however, is less evident. Although previous work has found a relationship between infant mortality and CHCs (Goldman and Grossman 1988), we do not find evidence of this relationship (Figure 7, panel A). This reflects both the relatively small sample sizes (infants deaths comprise a maximum of 2 percent of all deaths in this period) and the fact that sick infants would have continued to be treated at hospitals rather than at newly established CHCs. Notable is that the 95 percent confidence intervals include sizable changes of \pm 2 percent during the first five years CHCs operated. ${ }^{20}$ Similarly, Figure 7, panel B provides no evidence that $\mathrm{CHCs}$ reduced child deaths, though these estimates are also imprecise. The 95 percent confidence intervals include changes in child mortality rates as large as 4 percent in either direction. Finally, Figure 7, panel $\mathrm{C}$ shows little evidence of a

\footnotetext{
18 Additional robustness checks examine these specifications for the sample limited to the 114 treated counties. Online Appendix Figure E1 and Table E1 include region-by-year rather than state-by-year fixed effects due to collinearity concerns. The magnitude of the effects is similar in this sample (between -50 and -100 deaths per 100,000 after 10 years), but the estimates in specifications with and without time trends are less precise. The trend-break estimates show that older-adult mortality rate fell by 8 additional deaths (per $100,000)$ per year $($ s.e. $=5.7$ ) in the specification without county trends and by 6.7 deaths with county trends $($ s.e. $=5.6$ )

${ }^{19}$ Heterogeneity in CHCs' effects for ages 50 to 64, 65 to 79, and 80+ are in online Appendix Table G4.

${ }^{20}$ Goldman and Grossman $(1988$, p. 69) find that CHCs reduced infant mortality by 0.1 and 0.3 deaths per 1,000 live births, or by 0.5 and 1.5 percent of the 1970 baseline rate. Our design cannot rule out effects of this size.
} 
short-run relationship between adult deaths and $\mathrm{CHCs}$, but some evidence of a long-run relationship. This result partly reflects increases in sample size (adult mortality comprised around 10 percent of all deaths in this period), but is also consistent with CHCs' expected effects. Sustained access to primary care helps adults manage chronic and potentially lethal conditions, which would result in longer-term, (but not immediate) mortality reductions. The lag between $\mathrm{CHC}$ establishment and reductions in mortality for this group, however, suggest caution in interpreting this effect.

In summary, all-cause, age-adjusted mortality rates fell rapidly after CHCs began. A large share of this fall is attributable to reductions in mortality risk among individuals 50 and older. CHCs' effects on other age groups may have been less immediate and, owing to the relative rarity of preventable deaths in these groups, more difficult to detect. The data provide some evidence that $\mathrm{CHCs}$ benefitted younger adults over the longer-term, but we find no evidence of a relationship between CHCs and infant or child deaths.

\section{The Relationship between CHCs and Mortality by Cause of Death}

Heterogeneity in the relationship between CHCs and mortality rates by cause of death provides more information on the possible mechanisms for these effects and, in particular, the hypothesis that $\mathrm{CHCs}$ reduced the costs of detecting and managing chronic conditions. Table 3, panel A presents DD estimates by cause for adults 50 and older, the age group driving the mortality reductions. Using our baseline specification, column 1 presents estimates for all causes and columns 2 to 7 present estimates for six leading causes of death. The results show that the greatest mortality reductions occurred for CVD-related causes: 5 to 9 years after $\mathrm{CHCs}$ began, heart-disease-related mortality fell by 1.8 percent ( 27 deaths per 100,000 , column 2) and cerebrovascular-disease-related mortality fell by 4 percent ( 17 deaths per 100,000, column 3). These findings are consistent with CHCs increasing access to and decreasing costs for blood pressure testing and treatment (due to more convenient testing and cheaper medications), both of which would improve treatment compliance. Reductions in CVD-related deaths may also reflect increased counseling given at CHCs about the warning signs of a heart attack or stroke, or simple advice to improve diet or quit smoking.

The effects of CHCs, however, appear to have extended beyond controlling hypertension. Mortality due to cancer and diabetes also fell just after $\mathrm{CHCs}$ were established. In years 5 to 9 , deaths due to cancer were 1.8 percent lower (-11 deaths per 100,000, column 4 ), which may reflect increased longevity due to earlier detection. Deaths due to infectious diseases (column 5) and diabetes (column 6) were also lower, but these reductions are not statistically significant at conventional levels. In a falsification test, deaths due to accidents fail to register economically or statistically significant declines in any of the event-year groups (column 7).

One explanation for these patterns is the interaction of CHCs' auxiliary services with Medicare. For instance, CHCs could affect older adult mortality by increasing knowledge of and enrollment in Medicare (implemented in 1966) and by providing transportation to hospitals for the Medicare eligible. If an interaction with Medicare were driving our results, then we would not expect mortality rates to fall after $\mathrm{CHC}$ establishment for the Medicare 
ineligible. Table 3, panel $\mathrm{B}$, however, presents evidence contrary to this expectation. For those ages 50 to 64 (too young to be eligible for Medicare), mortality due to diseases of the heart (column 2) and cerebrovascular system (column 3) fell by 1.4 and 5.2 percent, respectively, in years 5 to 9 . Similarly, deaths due to cancer (column 4), infectious diseases (column 5), and diabetes (column 6) fell by 1.7, 4.4, and 7 percent, respectively, over the same time frame. Deaths by accident (column 7) are the only category not to improve after CHCs began, even though deaths due to this cause for 50 to 64 year olds occurred more often than those due to infectious disease and diabetes. This pattern of results is consistent with $\mathrm{CHCs}$ reducing mortality risk through their direct provision of primary care and low cost medications.

Another possible explanation for CHCs' effects is that they effectively provided health insurance for the under- or uninsured poor. If this were the main mechanism, then we would expect mortality rates not to fall after $\mathrm{CHC}$ establishment for the Medicare eligible-a group with generous and near universal health insurance. Yet, Table 3, panel $\mathrm{C}$ shows that estimates for individuals ages 65 and older were also large. Five to nine years after CHCs began, deaths due to heart disease (column 2) and cerebrovascular disease (column 3) were 1.9 and 3.8 percent lower. Mortality risk attributable to cancer was 2.0 percent lower (column 4). Reassuringly, deaths due to accidents were not significantly reduced.

In summary, the effects of CHCs on the Medicare ineligible (50 to 64 year olds) show that their overall health effects are not completely explained by an interaction with Medicarefunded services. Post-establishment reductions in deaths due to cancer, infectious diseases, and diabetes are consistent with CHCs promoting prevention, earlier diagnosis, and treatment compliance for a broad set of chronic conditions, including but not limited to hypertension. Moreover, CHCs' effects on the Medicare eligible recommend their potential for improving health outcomes for those with generous health insurance, suggesting that CHCs' primary care and auxiliary services complemented other medical services paid for by health insurance.

\section{Translation of Intention-to-Treat Effects into Average Treatment Effects on the Treated}

These intention-to-treat estimates (ITT) average the effect of CHCs over all county residents ages 50 and older, regardless of whether they benefited from CHC services. We use two approaches to approximate the implied average treatment effect on the "treated" (ATET) those who, as a consequence of CHC establishment, obtained direct or indirect benefits they would not have otherwise obtained. The first approach assumes that all poor, older adults in a county with a CHC program were "treated" even if they did not use the CHC facility. That is, CHCs affected both patients and their communities (through the eradication of infectious disease, knowledge spillovers, and reduced crowding in emergency rooms), but health effects were limited to the poor. Dividing the reduction in AMR (-61: Table 2 panel B, average over columns 1 to 4 for years 5 to 9 ) by the older adult poverty rate in 1965 (22 percent) yields an ATET of 278 deaths per 100,000.

The second approach more narrowly assumes that $\mathrm{CHCs}$ only benefited their patients. We use the 1970 SHSUE to approximate the share of respondents ages 50 and older who lived in treated counties that had used CHCs over a five-year period. This approach suggests that 
11 percent of all older adults in a county benefitted. ${ }^{21}$ Dividing the AMR reduction by this figure yields an estimated ATET of 546 deaths per 100,000 (-61/0.11). Of course, the ATETs could be even larger if some CHC users would have obtained the same services otherwise.

ATETs between 278 to 546 deaths per 100,000 are roughly one half to two thirds the size of Chay, Kim, and Swaminathan's (2011) estimate of Medicare's effects on one-year mortality rates. Using the 1966-1968 Mortality Followback Survey (MFS) to construct mortality rates by poverty status for those ages 50 and older, the ATETs suggest that CHCs reduced the annual AMR by 7 to 13 percent for the poor within a decade. ${ }^{22}$ Consistent with the argument that $\mathrm{CHCs}$ reduce health disparities, the effects are also equivalent to 20 to 40 percent of the mortality gap between the poor and the non-poor for this age group. The implied magnitudes are, therefore, plausible given the poor's higher mortality rates and the greater potential need for medical services among those using CHCs.

\section{Mechanisms for the Effects of Community Health Centers on Mortality}

Thus far we document a large positive relationship between the establishment of CHCs and reductions in older adult mortality for a broad set of causes of death. To understand the mechanisms for CHCs' mortality effects, this section examines effect heterogeneity by pretreatment community characteristics and then directly examines the role of increases in the use of primary care, anti-hypertensive drugs, and Medicare utilization.

\section{A. Heterogeneity in the Relationship of CHCs with Older Adult Mortality Rates}

Our heterogeneity analysis provides descriptive evidence relating to hypotheses in the historical literature. For ease of interpretation, we implement these tests by replacing the event-year dummies in equation (1) with $\sum_{k}\left(\sum_{g=-2}^{-1} \tilde{\pi}_{g}^{k} D_{j}^{k} D_{j}^{g}+\sum_{y=0}^{3} \tilde{\tau}_{g}^{k} D_{j}^{k} D_{j}^{g}\right)$, where $D_{j}^{k}$ is equal to 1 if a county received a CHC between 1965 and 1974 and belongs to group $k$ (defined subsequently).

\footnotetext{
${ }^{21}$ As a starting point, the SHSUE shows that 0.93 percent $(930 / 100,000)$ of those 50 and older had used "a clinic not connected with a hospital — such as a Board of Health clinic or neighborhood health center." 28 percent of older adults lived in CHC counties, which implies that 3.3 percent $(0.093 / 0.28)$ of residents 50 and older in counties with CHCs had used them by 1970 . We adjust this figure in two additional steps. First, we inflate the estimate to reflect the high degree of retrospective underreporting of clinic use. Bound, Brown, and Mathiowetz's (2001, p. 3813) survey of measurement error in the reporting of public program use shows that survey responses agree with administrative records as little as 50 percent of the time; survey responses agree with provider records of "clinic visits" as little as 39 percent of the time. This implies that the SHSUE one-year utilization rate may have been as high as 8.5 percent $(0.033 / 0.39=0.085)$. Second, we use nine surveys conducted by the OEO in CHC catchment areas between 1968 and 1972 to adjust the estimates for cumulative use over five years (see online Appendix A for details on data). For respondents 50 and older, 76 percent of physician visits that occurred in the previous five years took place one year prior to the survey, which inflates our estimates of 5year CHC use to 11.2 percent (similar to the PSU-level increase in the use of a "clinic" as a regular source of care reported in Section I). See online Appendix F for more details on these calculations. This analysis uses the survey weights to account for oversampling in 1970 of low income urban families (see Center for Health Administration Studies/National Opinion Research Center 1988). The ICPSR dictionary for this variable contains an error and so previous analyses using the SHSUE (Finkelstein and McKnight 2008) have not used weights. See online data Appendix A for details on this error.

${ }^{22}$ Vital Statistics mortality data do not contain information on income or education. The 1966-1968 National Mortality Followback Survey (US DHHS 1986) sampled death certificates from 1966 to 1968 and surveyed death record informants about the decedent's household income in 1965. Together with the 1965 CPS population estimates, these data allow us to compute mortality rates by income (King et al. 2010). This survey shows that the AMR for those 50 and older was 50 percent higher among those living in a household with a total income of less than the 1965 poverty line for a family of four $(<\$ 3,000)$ than among those above this threshold $(4,127$ versus 2,769$)$.
} 
One hypothesis in the literature is that CHCs reduced excess mortality-deaths that would not have occurred if individuals had access to primary care and treatment for chronic conditions. Although the $\mathrm{CHC}$ locations do not appear related to their pre-program mortality rates (Table 1, Figure 4), the excess mortality hypothesis suggests that $\mathrm{CHCs}$ could have larger effects in areas with higher mortality. The results in Table 4 bear this out. Areas with above-median mortality rates (column 2) experienced more than 4 times larger absolute and relative reductions in mortality rates than did areas with below-median mortality rates (column 1) 5 to 9 years after the $\mathrm{CHC}$ began; the reduction was approximately seven times as high in the above- median group in years 10 to 14 .

A second hypothesis is that CHCs would have larger effects in areas that were underserved by physicians (MDs). Table 4, however, is inconsistent with this hypothesis. Rather, areas with more physicians per capita in 1960 saw a 40 percent greater absolute reduction in mortality rates 5 to 9 years after $\mathrm{CHCs}$ began. The proportional reductions were 2.4 percent in the high-MD counties $(-79 / 3,252$, column 4$)$ and 1.8 percent in the low-MD counties $(-56 / 3,049$, column 3$)$, but we fail to reject the hypothesis that reductions in mortality rates were equal across these groups $(p$-value $=0.72) .{ }^{23}$ This evidence suggests that the convenience or affordability of care may be more important than CHCs' direct provision of physicians in underserved areas.

A third hypothesis is that CHCs benefitted nonwhite more than white families, both because nonwhite families tended to have lower incomes and also because War on Poverty programs actively sought to ameliorate racial disparities. In contrast, Table 4 shows that the results for white mortality (column 6) are larger and more precise than those for nonwhites (column 5), although the estimates are not statistically different ( $p$-value $=0.31)$. One explanation is the higher noncompliance of nonwhites with prescribed treatments (Simeonova 2013). Another explanation is that fewer nonwhites had heard of CHCs, as shown by surveys in the 1960s in 11 cities of CHC catchment areas (online Appendix Table F3). Yet another explanation is that "frailty" differed between older white and nonwhite adults (Manton and Stallard 1984). If nonwhites had higher mortality rates at younger ages, then this would lead to a healthier surviving population of nonwhite adults after age 50-adults who had less to gain from $\mathrm{CHC}$ care.

A final hypothesis is that CHCs' effects may have been largest in the South-the census region with the most poverty and unmet medical need. Table 4's estimates also fail to support this hypothesis. The relationship between CHCs and mortality rates is statistically indistinguishable in specifications that omit the South (column 9) and those that omit other regions (columns 7, 8, and 10). The effects of CHCs appear in all census regions.

These results suggest that primary care and the management of chronic conditions were important mechanisms for CHCs' mortality effects among older adults. CHCs' effects were largest in areas with the highest pre-program mortality rates, in urban areas, and in areas with more (not fewer) physicians per capita. Their effects do not appear to be driven by the

${ }^{23}$ This may reflect the positive correlation between per capita MDs and a county's urban share, which Figure 6 shows to be associated with the effects of CHCs. Three quarters of treated counties with urban shares above (below the median have per capita MD values above (below) the median as well. 
provision of health care professionals to underserved areas (i.e., those with few MDs, those with higher poverty rates, or those in the South) or to be concentrated among nonwhites or in the South.

\section{B. Did CHCs Increase the Use of Primary Care and Prescription Drugs?}

The 1963 and 1970 SHSUE provide direct evidence of CHCs' role in increasing the use of primary care and prescription medications. For ease of interpretation, we estimate the simple DD model described in Section IA separately for three household income groups relative to the poverty line: less than 100 percent, 101 to 299 percent, and 300 percent and above. The results presented in Table 5 provide strong evidence that CHCs increased the likelihood of older adults in poverty reporting a "regular source of care" by around 23 percent $(0.18 / 0.76$, column 1). Reporting a regular source of care is a stronger predictor of positive health outcomes than is having health insurance (Sox et al. 1998); it is also highly correlated with compliance with anti-hypertension treatment (Shea et al. 1992). Other evidence on utilization is also consistent with CHCs increasing patient's use of medical care on the intensive margin through better attachment to a regular care source. The point estimate for the total number of visits among poor older adults suggests a 38 percent (albeit imprecise) increase (2.66/6.96, column 2), but CHCs are not associated with large increases in the likelihood of seeing a physician in the previous year (column 3). In addition, CHCs are associated with a reduction of almost one third in the likelihood of paying for prescription drugs out of pocket among older adults in poverty $(-0.18 / 0.56$, column 4$)$. In contrast, changes of these magnitudes are not evident among higher income individuals in areas that received CHCs (Table 5, panels B and C). The same outcomes generally have the opposite signs, are smaller in magnitude, and are statistically insignificant. This evidence is consistent with the fact that the near poor used CHCs' in-house pharmacies, which likely increased their compliance with medication regimens.

\section{How Important Were Changes in the Use of Anti-Hypertensive Medications?}

The findings that CHCs reduced the probability of out-of-pocket prescription drug expenditures, served as a regular source of care for the poor, and reduced CVD-related deaths all suggest that they may have improved access to anti-hypertensive medications for affected patients. A back-of-the-envelope calculation allows us to evaluate anti-hypertensive medications as a mechanism. To this end, we use the 1973 Hypertension Detection and Follow-up Program (HDFP) - a large community-based, randomized trial of the mortality effects of hypertension drug treatment over five years. ${ }^{24}$ HDFP participants ages 50 to 70 who were prescribed anti-hypertensive drugs and provided with stepped-up care (similar to the outreach and follow-up provided by $\mathrm{CHCs}$ ) experienced a reduction in five-year, allcause mortality rates of $-2,160$ deaths per 100,000 (HDFP 1979; Table 9). To translate this result into a population-level effect (not just for hypertensives as in the HDFP), we multiply

\footnotetext{
${ }^{24}$ The 1973 HDFP trial obtained a sample of over 10,000 participants with hypertension (diastolic blood pressure over $90 \mathrm{~mm} \mathrm{Hg}$ ). A randomly selected treatment group saw HDFP staff on a flexible schedule, received frequent follow-up, and, importantly, was prescribed anti-hypertensive medication. The control group learned about their hypertension and was referred to their usual source of care (and may have taken anti-hypertensive drugs). The HDFP did not assess the role of screening and diagnosis (all participants were screened and informed of their hypertension), but the treatment group received anti-hypertensive drugs and auxiliary services similar to the services provided by CHCs.
} 
this treatment effect by the share of people with hypertension (26.2 percent, National Health Examination Survey) and also by the share in treated communities who used CHCs (16 percent, Section IIID). If CHCs provided anti-hypertensive medication but no screening (as in the HDFP study), the aggregate, age-adjusted five-year mortality rate would have fallen by 91 deaths $(2,160 \times 0.262 \times 0.16)$ per 100,000 . This estimate understates CHCs' effects on hypertension-related mortality through screening, education, and other channels.

To facilitate a comparison, we translate our ITT estimates of one-year mortality reductions for years 5 to 9 ( -61 , Table 2, panel B) into a five-year mortality reduction using the mean age-adjusted mortality rate in year $-1(3,213$ deaths per 100,000 , Table 2$)$ as the counterfactual mortality rate. Our estimates imply a reduction of 264 death [ $=(1-$ $0.03213)^{5}-(1-(0.03213-0.0006))^{5}$ ] per 100,000 in five-year mortality rates. Comparing this estimate to the HDFP results implies that treatment for hypertension could account for 34 percent (91/264) of our ITT effects. In short, anti-hypertensive medication could be an important part of the story, but it does not appear to be the entire story. ${ }^{25} \mathrm{CHCs}$ ' medical and auxiliary services likely improved the prevention, detection, and management of other chronic conditions among older adults and, consequently, also reduced the incidence of nonCVD related mortality rates.

\section{Did CHCs Increase the Use of Medicare?}

For the elderly, CHCs may also reduce mortality by complementing services provided by Medicare. Although CHCs did not collect Medicare reimbursements in this period, they may have increased knowledge about and use of Medicare-covered services (e.g., via counseling and transportation to hospitals). To examine this channel, we estimate our baseline model using as dependent variables real, county-level per capita military and Medicare expenditures (available from 1959 to 1988, Figure 8, panel A) and Medicare per-enrollee expenditures (available for 1966 forward, Figure 8, panel B). ${ }^{26}$ If the effects of CHCs on elderly mortality arose primarily through increased use of Medicare-funded hospital treatments such as bypass surgery, then we should see per-enrollee Medicare spending increase after CHCs began. Figure 8, however, provides little evidence of such a relationship. Total per capita medical spending evolved smoothly before and after $\mathrm{CHCs}$ began, and per-enrollee Medicare expenditures did not increase differentially after CHCs began (panel A). The absence of large aggregate changes, however, could imply no effect or offsetting effects. On the one hand, CHCs could increase awareness of Medicare while, on the other, they could reduce the need for Medicare-covered services. If greater awareness led some patients to use Medicare-covered services while diverting others from hospitals, $\mathrm{CHCs}$ could have no net effect on Medicare expenditure per capita or per enrollee (although they would increase efficiency). Panel B provides suggestive evidence of patient diversion. In fact, $\mathrm{CHCs}$ appear to have reduced Medicare enrollment $(p$-value $=0.013$ on a joint test that

\footnotetext{
${ }^{25}$ As a comparison, the RAND Health Insurance Experiment found that nearly half of the reduction in blood pressure difference between those receiving free care and those with co-payment plans was attributable to the onetime initial blood pressure screening (Newhouse et al. 1993, pp. 229, 243).

26 Because information on all per capita medical expenditures is available from 1959 to 1988, Figure 8, panel A presents estimates for this outcome from -6 forward. In the specifications using Medicare administrative data, available from 1966 forward, we omit the pretreatment coefficients from the figure because they are not based upon a balanced set of counties. In Figure 8, panel B, we exclude counties with CHCs established before 1966 for the same reason.
} 
post-coefficients are not zero), suggesting that some elderly patients could have used CHCs rather than hospitals. In summary, the available evidence points to longer-term benefits of primary care and lower-cost medication provided by $\mathrm{CHCs}$ as mechanisms for mortality effects. Interactions of $\mathrm{CHC}$ care with public insurance provided by Medicare do not seem to be important factors driving their mortality effects.

\section{Alternative Explanations? Potential Threats to Internal Validity}

This final section examines potential threats to the internal validity of the study, which include local shocks that both reduce mortality and occur concurrently with or just after CHCs began. For instance, coincident changes in other federal spending (e.g., other OEO programs), other local medical resources, or Medicaid coverage could influence our estimates. We first investigate whether $\mathrm{CHC}$ establishment coincided with other federal OEO grants using newly compiled data on grants for other federal programs. This could have happened inadvertently or because certain communities were more effective in obtaining funding (e.g., more affluent urban areas, Table 1). Large coincident increases in other federal funding that also reduced older adult mortality could threaten the internal validity of our estimates. ${ }^{27}$ To investigate this, we estimate regressions similar to equation (1) and replace the dependent variable with a binary measure equal to 1 if county $j$ received a grant for a program in year $t$. Figure 9, panel A shows little evidence that $\mathrm{CHC}$ establishment coincided with increases in other local funding. We use a binary variable equal to 1 if a county received a $\mathrm{CHC}$ grant (thick line, no markers). By construction, the estimates reach one in the year $\mathrm{CHCs}$ began (100 percent of treated counties received a CHC grant in event-year 0). The share tapers to around 50 percent five years later as some $\mathrm{CHCs}$ received multi-year grants. ${ }^{28}$ For our estimates to confound changes in other federal funding with $\mathrm{CHCs}$, grants for other programs would need to show a similar level shift or trendbreak around year 0 . No such patterns emerge, however, for other Community Action Program (CAP) health projects, CAP administration (including local development projects), programs serving the elderly, Head Start, legal services, or Food Stamps. We cannot rule out funding changes in programs we do not measure, but these patterns are reassuring. ${ }^{29}$

We next investigate whether the establishment of CHCs coincided with local changes in other health resources as proxied by local hospital capacity. This could be the case if, for instance, the leading-edge individual getting the $\mathrm{CHC}$ grant also received a grant to increase local hospital size or if Hill Burton diagnostic centers (part of hospitals) expanded at the same time. Based on data from 1948 to 1990 from the American Hospital Association's (AHA) Annual Survey, Figure 9, panel B provides little evidence that either occurred. Using the number of hospitals and the number of hospital beds (both measured per 1,000 residents) as dependent variables, the estimates show that both outcomes evolved smoothly before and

\footnotetext{
${ }^{27}$ Evidence that other OEO programs reduced mortality makes this a reasonable concern. Ludwig and Miller (2007) document the relationship between Head Start and child mortality and Almond, Hoynes, and Schanzenbach (2011) document the relationship between Food Stamps and infant mortality. These programs could benefit older adults indirectly by freeing up or increasing family resources.

${ }^{28}$ For instance, 92 percent of locations treated before 1975 also received a federal grant between 1978 and 1980 . Only a handful of CHCs closed over the entire period we consider.

${ }^{29}$ Note that a coincident expansion of, say, local health programs in response to a CHC would not confound our estimates, but would represent another causal channel ("crowd-in") through which CHCs reduced mortality
} 
after the establishment of CHCs. The absence of a trend-break in hospital beds per capita $(0.008$, s.e. 0.017$)$ provides little evidence that we misattributed changes in local hospital capacity to CHCs. Moreover, the trend break in the number of hospitals shows that medical resources in untreated areas worked against the mortality reductions we find. Specifically, the marginally significant slowdown in the growth of the number of hospitals after $\mathrm{CHCs}$ began $(-0.0002$, s.e. 0.0001$)$ is consistent with areas without CHCs catching up to areas receiving CHCs. If growing hospital resources reduced mortality rates in areas without $\mathrm{CHCs}$, this should work against the mortality effects we find.

A final explanation for the mortality effects of $\mathrm{CHCs}$ is that counties with $\mathrm{CHCs}$ may have benefited disproportionately from Medicaid. Whereas our baseline model accounts for Medicaid's state-level roll-out by using state-by-year fixed effects, Medicaid's effects may have been larger in the poorer, urban areas also served by CHCs (for reasons unrelated to $\mathrm{CHCs}){ }^{30}$ To evaluate this, we include dummies for event time relative to state Medicaid implementation interacted with county-level characteristics such as high 1960 poverty rates, high numbers of active physicians, and the presence of a medical school. Our estimates of CHCs' effects, however, remain similar in magnitude and statistically indistinguishable from our baseline estimates (online Appendix Figure E3). Overall, we find little evidence that correlated local shocks in federal spending, medical resources, or state Medicaid programs compromise the internal validity of our research design.

\section{The Longer-Term Returns to Primary Care}

Since 1965, the CHC experiment has been an important yet understudied part of the US health care safety net—not least because the CHC program costs so much less than Medicare and Medicaid. Even recent political support for $\mathrm{CHCs}$ relates, in part, to their role as an alternative to expanding public health insurance (Mickey 2012). An important lesson from our analysis is that public investments in the delivery of primary care may yield large returns for the underserved and underinsured population—even to those eligible for Medicare.

The CHC program's rollout from 1965 to 1974 presents a rare opportunity to quantify the effects of changes in access to primary care among the underserved. Within an event-study framework, our empirical strategy exploits the disorganized grant-making process during the early years of the War on Poverty. Consistent with accounts of "great administrative confusion" at the OEO (Levine 1970), our data show no association of CHC program establishment with a variety of pre-treatment county characteristics: 1965 mortality rates, changes in mortality rates from 1960 to 1965, funding for other OEO programs, or local expansions in hospital capacity. The establishment of a $\mathrm{CHC}$, however, predicts sharp reductions in older-adult mortality.

Our results imply that CHC-induced increases in primary care led to sustained health improvements over at least 15 years. One decade after CHCs were established, age-adjusted

\footnotetext{
${ }^{30}$ Regressing the year in which a CHC was established on the year in which Medicaid was passed results in a correlation of 0.071 (s.e. 0.081). Excluding Arizona, which is an outlier as a late Medicaid adopter, the correlation is 0.216 (s.e. 0.150). State-wide effects of Medicaid are captured in the specifications with state-by-year fixed effects.
} 
all-cause mortality rates remained almost 2 percent lower than pre-program rates, owing primarily to large reductions in cardiovascular-related deaths among adults over age 50 . The implied treatment effects on the treated are a 7 to 13 percent reduction in age-adjusted mortality rates among residents likely to have benefited from CHCs, which amounts to a 20 to 40 percent reduction in the 1966 poor non-poor mortality gap for the same age group. Some of CHCs' longer-term benefits accrued to individuals ineligible for Medicare (ages 50 to 64), but the program achieved large mortality reductions among the Medicare eligible without an accompanying increase in Medicare spending. Important reasons for this may be that $\mathrm{CHCs}$ reduced the cost of prevention, diagnosis, and management of chronic conditions and provided free or substantially discounted prescription medications.

What do these findings imply about the cost-effectiveness of CHCs relative to other public health interventions? Assuming that mortality is the only outcome CHCs affected, we estimate CHCs' cost per year-of-life gained. Multiplying our baseline estimates (Figure 7, panel D) by the older adult population in treated counties during CHCs' first ten years implies 81,644 years of life gained after CHCs began. We obtain the total cost of the CHC program over its first ten years by estimating the average annual federal cost of CHCs and multiplying by the $114 \mathrm{CHCs}$ in our sample. This yields a total of $\$ 4.4$ billion in 2012 dollars and a cost-per-year-of-life ratio of approximately $\$ 54,000$.

The cost-effectiveness of Medicare at implementation provides a natural point of comparison. Using Chay, Kim, and Swaminathan's (2011) regression-discontinuity estimates of Medicare's effects on elderly mortality at the time of implementation and our data on total Medicare expenditures suggests a cost-per-year-of-life ratio ranging from approximately $\$ 2.5$ to $\$ 7.1$ million in 2012 dollars. ${ }^{31}$ Scaling these estimates by remaining life expectancy (Chay, Kim, and Swaminathan 2011 estimate 14.5 years) reduces the cost per one year of life to between $\$ 161,373$ and $\$ 459,000$ in 2012 dollars -3 to 8 times the ratio for $\mathrm{CHCs}$ established in the same period. Adjusting the $\mathrm{CHC}$ cost-ratios for the program's impact on life expectancy could further shift these calculations in CHCs' favor. Both ratios are considerably less than the value of a statistical life in Ashenfelter and Greenstone (2004), who cite a preferred estimate of \$2.19 million in 2012 dollars ( $\$ 1.54$ million in 1997 dollars), and much lower than earlier surveys (Viscusi 1992; Manning et al. 1989).

These cost ratios likely understate the broader effects of increasing access to primary care by expanding $\mathrm{CHCs}$, because mortality fails to capture changes in morbidity, disability, and other gains in health and well-being. These conservative cost ratios, however, suggest that CHCs achieved their primary objective of improving health at much lower cost than larger public insurance programs - especially for the elderly. Whether CHCs' health benefits remain this large today and whether $\mathrm{CHC}$ s benefited the non-elderly remain important areas for future research.

\footnotetext{
${ }^{31}$ Chay, Kim, and Swaminathan (2011) present much smaller cost-effectiveness estimates based on total gains in life expectancy and the additional spending on inpatient hospital care induced by Medicare. Here we use the average annual total cost of Medicare.
} 


\section{Acknowledgments}

This project was generously supported by the National Institutes of Health (R03-HD066145, R01-HD070950, and L60-MD003213), the University of California-Berkeley's Center on the Economics and Demography of Aging (NIA 2P30AG012839), the University of Michigan's Robert Wood Johnson Foundation Health and Society Scholars Small Grant Program, the University of Michigan's Population Studies Center's Eva Mueller Award, and the West Coast Poverty Center (US DHHS, Office of the Assistant Secretary for Planning and Evaluation, 3 U01 PE000004-03S3). The opinions and conclusions expressed herein are solely those of the authors and should not be construed as representing the opinions or policy of any agency of the federal government. We gratefully acknowledge the use of the services and facilities of the Population Studies Center at the University of Michigan (funded by NICHD Center Grant R24 HD041028). During work on this project, Goodman-Bacon was supported by the NICHD (T32 HD0007339) as a UM Population Studies Center Trainee. We are grateful to Doug Almond, Hilary Hoynes, and Diane Schanzenbach for sharing the Regional Economic Information System (REIS) data for the period of 1959 to 1978; Amy Finkelstein for sharing the American Hospital Association (AHA) Annual Survey data from 1948 to 1974; Jean Roth for sharing the AHA data from 1976 to 1990; Cynthia Severt and the University of Wisconsin DISC for helping us locate and compile the OEO survey data; and Cheryl Sutherland and Jeffrey Hackett from NORC for helping us locate the restricted geographic identifiers in the SHSUE. We are also grateful for helpful comments from Barbara Anderson, John Bound, Charlie Brown, Amitabh Chandra, Jamein Cunningham, John DiNardo, Nic Duquette, Daniel Eisenberg, Mireille Jacobson, Bob Kaestner, David Lam, Ron Lee, Maggie Levenstein, Daniel Leeds, Rob Mickey, Sayeh Nikpay, Edward Norton, Paul Rhode, Heather Royer, Mel Stephens, Jeff Smith, Kathy Swartz, John Wilmoth, and Bobbi Wolfe. Exceptional research assistance was provided by Shulamite Chiu, Andrew Covert, Emily Gray Collins, Allison Davido, Anna Erickson, Kendra Goostrey, Johannes Norling, Tyler Sawher, and Anna Wentz.

\section{References}

Adashi, Eli; Geiger, H Jack; Fine, Michael D. Health Care Reform and Primary Care-The Growing Importance of the Community Health Center. New England Journal of Medicine. 2010; 362(22): 2047-50. [PubMed: 20427777]

Almond, Douglas; Chay, Kenneth; Greenstone, Michael. MIT Department of Economics Working Paper 07-04. 2006. Civil Rights, the War on Poverty, and Black-White Convergence in Infant Mortality in the Rural South and Mississippi.

Almond, Douglas; Hoynes, Hilary W.; Schanzenbach, Diane Whitmore. Inside the War on Poverty: The Impact of Food Stamps on Birth Outcomes. Review of Economics and Statistics. 2011; 93(2): $387-403$.

American Hospital Association (AHA). Annual Survey of Hospitals. Chicago: AHA; 1948-1990.

Arellano M. Computing Robust Standard Errors for Within-Groups Estimators. Oxford Bulletin of Economics and Statistics. 1987; 49(4):431-34.

Ashenfelter, Orley; Michael, Greenstone. Using Mandated Speed Limits to Measure the Value of a Statistical Life. Journal of Political Economy. 2004; 112(1):S226-67.

Bailey, Martha J. Reexamining the Impact of Family Planning Programs on US Fertility: Evidence from the War on Poverty and the Early Years of Title X. American Economic Journal: Applied Economics. 2012; 4(2):62-97. [PubMed: 22582135]

Bailey, Martha J.; Nicolas, J Duquette. How Johnson Fought the War on Poverty: The Economics and Politics of Funding at the Office of Economic Opportunity. Journal of Economic History. 2014; 74(2):351-88. [PubMed: 25525279]

Bailey, Martha J.; Goodman-Bacon, Andrew. The War on Poverty's Experiment in Public Medicine: Community Health Centers and the Mortality of Older Americans: Dataset. American Economic Review. 2015. http://dx.doi.org/10.1257/aer.20120070

Bell, Ronny A.; Camacho, Fabian; Goonan, Kelly; Duren-Winfield, Vanessa; Anderson, Roger T.; Konen, Joseph C.; Goff, David C. Quality of Diabetes Care Among Low-Income Patients in North Carolina. American Journal of Preventive Medicine. 2001; 21(2):124-31. [PubMed: 11457632]

Bellin, Seymour S.; Geiger, HJ.; Gibson, Count D. Impact of Ambulatory-Health-Care Services on the Demand for Hospital Beds. New England Journal of Medicine. 1969; 280(15):808-12. [PubMed: 5773640]

Bound, John; Brown, Charles; Mathiowetz, Nancy. Measurement Error in Survey Data. In: Heckman, James J.; Leamer, Edward, editors. Handbook in Econometrics. Vol. 5. Amsterdam: Elsevier; 2001. p. 3707-3843. 
Center for Health Administration Studies/National Opinion Research Center. Survey of Health Services Utilization and Expenditures, 1970. Ann Arbor, MI: Inter-university Consortium for Political and Social Research [producer and distributor]; 1981. Conducted by University of Chicago, Center for Health Administration Studies/National Opinion Research Center. ICPSR ed

Center for Health Administration Studies/National Opinion Research Center. Health Services Utilization and Expenditures, 1963. 3. Ann Arbor, MI: Inter-university Consortium for Political and Social Research [producer and distributor]; 1988.

Chabot, Andre. Improved Infant Mortality Rates in a Population Served by a Comprehensive Neighborhood Health Program. Pediatrics. 1971; 47(6):989-94. [PubMed: 5141768]

Chay, Kenneth Y.; Kim, Daeho; Swaminathan, Shailender. Medicare, Hospital Utilization and Mortality: Evidence from the Program's Origins. 2011. Unpublished

Chin, Marshall H.; Steven, B.; Auerbach, Sandy; Cook, James F.; Harrison, Julie; Koppert, Lei Jin; Fay, Thiel, et al. Quality of Diabetes Care in Community Health Centers. American Journal of Public Health. 2000; 90(3):431-34. [PubMed: 10705866]

Crimmins, Eileen M. The Changing Pattern of American Mortality Decline, 1940-77, and Its Implications for the Future. Population and Development Review. 1981; 7(2):229-54.

Crump, Richard K.; Hotz, V Joseph; Imbens, Guido W.; Oscar, A Mitnik. Dealing with Limited Overlap in Estimation of Average Treatment Effects. Biometrika. 2009; 96(1):187-99.

Cunningham PJ. Medicaid/SCHIP Cuts and Hospital Emergency Department Use. Health Affairs. 2006; 25(1):237-47. [PubMed: 16403760]

Currie, Janet; Jonathan, Gruber. Health Insurance Eligibility, Utilization of Medical Care, and Child Health. Quarterly Journal of Economics. 1996a; 111(2):431-66.

Currie, Janet; Jonathan, Gruber. Saving Babies: The Efficacy and Cost of Recent Changes in the Medicaid Eligibility of Pregnant Women. Journal of Political Economy. 1996b; 104(6):1263-96.

Cutler, David M.; Kadiyala, Srikanth. The Return to Biomedical Research: Treatment and Behavioral Effects. In: Murphy, Kevin M.; Topel, Robert H., editors. Measuring Gains from Medical Research. Chicago: University of Chicago Press; 2003. p. 110-62.

Cutler, David; Meara, Ellen. National Bureau of Economic Research Working Paper 8556. 2001. Changes in the Age Distribution of Mortality Over the $20^{\text {th }}$ Century.

Davis, Karen; Schoen, Cathy. Health and the War on Poverty: A Ten Year Appraisal. Washington, DC: The Brookings Institution; 1978.

Department of Health, Education, and Welfare (DHEW). A Directory of Selected Community Health Services Funded Under Section 314(e) of the Public Health Service Act, July 1971. Rockville, MD: Community Health Service Division of Health Care Services; 1972a.

Department of Health, Education, and Welfare (DHEW). A Directory of Selected Community Health Services Funded Under Section 314(e) of the Public Health Service Act, July 1972. Rockville, MD: Community Health Service Division of Health Care Services; $1972 b$.

Deprez, Ronald D.; Pennell, Beth-Ellen; Libby, Mary Anne. The Substitutability of Outpatient Primary Care in Rural Community Health Centers for Inpatient Hospital Care. Health Services Research. 1987; 22(2):207-33. [PubMed: 3301745]

Dignan MB, Hall MB, Hastings DW. Effect of Increased Access to Health Care on Mortality from Cardiovascular Disease in Rural Tennessee. Public Health Reports. 1979; 94(2):186-92. [PubMed: 432413]

DiNardo, John; Fortin, Nicole M.; Lemieux, Thomas. Labor Market Institutions and the Distribution of Wages, 1973-1992: A Semiparametric Approach. Econometrica. 1996; 64(5):1001-44.

Economic Opportunity Act (EOA). Public Law. 1964. p. 88-452.

Epstein AJ. The Role of Public Clinics in Preventable Hospitalizations among Vulnerable Populations. Health Services Research. 2001; 36(2):405-20. [PubMed: 11409820]

Falik, Marilyn; Needleman, Jack; Herbert, Robert; Wells, Barbara; Politzer, Robert; Benedict, M Beth. Comparative Effectiveness of Health Centers as Regular Source of Care. Journal of Ambulatory Care Management. 2006; 29(1):24-35. [PubMed: 16340617]

Finkelstein, Amy; Robin, McKnight. What Did Medicare Do? The Initial Impact of Medicare on Mortality and Out of Pocket Medical Spending. Journal of Public Economics. 2008; 92(7):164468. 
Freeman, Howard E.; Kiecolt, K Jill; Allen, Harris M, II. Community Health Centers: An Initiative of Enduring Utility. The Milbank Memorial Fund Quarterly Health and Society. 1982; 60(2):245-67. [PubMed: 6919771]

Freis, Edward D. Historical Development of Antihypertensive Treatment. In: Laragh, JH.; Brenner, BM., editors. Hypertension Pathophysiology, Diagnosis, and Management. Second. New York: Raven Press; 1995. p. 2741-51.

General Accounting Office (GAO). Implementation of a Policy of Self-Support by Neighborhood Health Centers, B-164031(2). Washington, DC: Comptroller General of the United States; 1973.

Gillette, Michael L. Launching the War on Poverty: An Oral History. New York: Twayne Publishers; 1996.

Goldman L, Cook E Francis. The Decline in Ischemic Heart Disease Mortality Rates: An Analysis of the Comparative Effects of Medical Interventions and Changes in Lifestyle. Annals of Internal Medicine. 1984; 101(6):825-36. [PubMed: 6388454]

Goldman, Fred; Michael, Grossman. The Impact of Public Health Policy: The Case of Community Health Centers. Eastern Economic Journal. 1988; 14(1):63-72.

Goodman-Bacon, Andrew. Public Insurance and Mortality: Evidence from Medicaid Implementation. 2013. Unpublished

Gordis, Leon. Effectiveness of Comprehensive-Care Programs in Preventing Rheumatic Fever. New England Journal of Medicine. 1973; 289(7):331-35. [PubMed: 4740466]

Haines, Michael R.; The Inter-University Consortium for Political and Social Research. Historical, Demographic, Economic, and Social Data: The United States, 1790-2002 [Computer file]. ICPSR02896-v3. Ann Arbor, MI: Inter-University Consortium for Political and Social Research [distributor]; 2005. 2005

Harrington, Michael. The Other America: Poverty in the United States. New York: Simon \& Schuster; 1962.

Hawkins D Jr, Schwartz R. Health Centers and the States: Partnership Potential to Address the Fiscal Crisis. Journal of Ambulatory Care Management. 2003; 26(4):285-95. [PubMed: 14567272]

Health Services Administration, Bureau of Community Health Services. Comprehensive Health Service Projects, Summary of Project Data. Rockville, MD: Department of Health Education and Welfare; 1974.

Heckman, James J.; Ichimura, Hidehiko; Smith, Jeff; Petra, Todd. Characterizing Selection Bias Using Experimental Data. Econometrica. 1998; 66(5):1017-98.

Hedberg, Viking A.; Byrd, Robert S.; Klein, Jonathan D.; Auinger, Peggy; Weitzman, Michael. The Role of Community Health Centers in Providing Preventive Care to Adolescents. Archives of Pediatrics and Adolescent Medicine. 1996; 150(6):603-08. [PubMed: 8646310]

Hicks, LeRoi S.; O’Malley, A James; Lieu, Tracy A.; Keegan, Thomas; Cook, Nakela L.; McNeil, Barbara J.; Landon, Bruce E.; Edward, Guadagnoli. The Quality Of Chronic Disease Care In U.S. Community Health Centers. Health Affairs. 2006; 25(6):1712-23. [PubMed: 17102197]

Hochheiser, Louis I.; Woodward, Kenneth; Charney, Evan. Effect of the Neighborhood Health Center on the Use of Pediatric Emergency Departments in Rochester, New York. New England Journal of Medicine. 1971; 285(3):148-52. [PubMed: 5087704]

Horowitz, Joel L. The Bootstrap. In: Heckman, James J.; Leamer, Edward, editors. Handbook of Econometrics. Vol. 5. Amsterdam: Elsevier; 2001. p. 3159-228.

Hoynes, Hilary W.; Page, Marianne E.; Stevens, Ann Huff. Can Targeted Transfers Improve Birth Outcomes? Evidence from the Introduction of the WIC Program. Journal of Public Economics. 2011; 95(7-8):813-27.

Hoynes, Hilary W.; Diane, Schanzenbach. Consumption Reponses to In-Kind Transfers: Evidence from the Introduction of the Food Stamp Program. American Economic Journal: Applied Economics. 2009; 1(4):109-39.

Hudson CL. Inaugural Address: Finding Our Way on a Path to the Future. Journal of the American Medical Association. 1966; 197(2):97-99. [PubMed: 5952507]

Hypertension Detection and Follow-Up Program Cooperative Group (HDFP). Five-Year Findings of the Hypertension Detection and Follow-up Program: II. Mortality by Race-Sex and Age. Journal of the American Medical Association. 1979; 242(23):2572-7. [PubMed: 490883] 
Iglehart, John K. Health Centers Fill Critical Gap, Enjoy Support. Health Affairs. 2010; 29(3):343-45. [PubMed: 20194970]

Jacobson, Louis S.; LaLonde, Robert J.; Sullivan, Daniel G. Earnings Losses of Displaced Workers. American Economic Review. 1993; 83(4):685-709.

Jeong, Jinook; Maddala, GS. A perspective on application of bootstrap methods in Econometrics. In: Maddala, GS.; Rao, CR.; Vinod, HD., editors. Handbook of Statistics 11: Econometrics. Amsterdam: Elsevier; 1993. p. 573-610.

Johnson, Lyndon B. Annual Message to Congress on the State of the Union. The American Presidency Project. 1964. January 8, 1964. Online by Gerhard Peters and John T. Woolleyhttp:// www.presidency.ucsb.edu/ws/?pid=26787 (accessed January 22, 2015)

Judd, Leda; Anderson, Elizabeth; Manseau, William; May, Jude Thomas; New, Peter. The Neighborhood Health Center Program: Its Growth and Problems, an Introduction. Washington, DC: National Association of Neighborhood Health Centers; 1976.

King, Miriam; Ruggles, Steven; Alexander, J Trent; Flood, Sarah; Genadek, Katie; Schroeder, Matthew B.; Trampe, Brandon; Vick, Rebecca. Integrated Public Use Microdata Series, 1965 Current Population Survey: Version 3.0 [Machine-readable database]. Minneapolis University of Minnesota; 2010.

Knowles, John H. The Medical Center and the Community Health Center. Bulletin of the NY Academy of Medicine. 1964; 40(9):713-42.

Lee KS, Paneth N, Gartner LM, Pearlman MA, Gruss L. Neonatal mortality: an analysis of the recent improvement in the United States. American Journal of Public Health. 1980; 70(1):15-21. [PubMed: 7350819]

Levine, Robert A. The Poor Ye Need Not Have with You: Lessons from the War on Poverty. Cambridge, MA: MIT Press; 1970.

Long, Genia; Cutler, David; Berndt, Ernst R.; Royer, Jimmy; Fournier, Andrée-Anne; Sasser, Alicia; Cremieux, Pierre. National Bureau of Economic Research Working Paper 12096. 2006. The Impact of Antihypertensive Drugs on the Number and Risk of Death, Stroke and Myocardial Infarction in the United States.

Sasso, Lo; Anthony, T.; Gayle, R Byck. Funding Growth Drives Community Health Center Services. Health Affairs. 2010; 29(2):289-96. [PubMed: 20348076]

Ludwig, Jens; Douglas, L Miller. Does Head Start Improve Children's Life Chances? Evidence from a Regression Discontinuity Design. Quarterly Journal of Economics. 2007; 122(1):159-208.

Manning, Williard G.; Keeler, EB.; Newhouse, JP.; Sloss, EM.; Wasserman, J. The Taxes of Sin: Do Smokers and Drinkers Pay Their Way? Journal of the American Medical Association. 1989; 261(11):1604-09. [PubMed: 2918654]

Manton, Kenneth G.; Stallard, Eric. Recent Trends in Mortality Analysis: Studies in Population. Orlando: Academic Press; 1984.

May, Jude Thomas; Durham, Mary L.; Kong-Ming, Peter. New Structural Conflicts in the Neighborhood Health Center Program: The National and Local Perspectives. Journal of Health Politics, Policy and Law. 1980; 4(4):581-604.

Mickey, Robert W. Dr. StrangeRove; or, How Conservatives Learned to Stop Worrying and Love Community Health Centers. In: Hall, Mark A.; Rosenbaum, Sara, editors. The Health Care "Safety Net" in a Post-Reform World. New Brunswick, NJ: Rutgers University Press; 2012. p. 21-66.

Moore, Gordon T.; Bernstein, Roberta; Bonanno, Rosemary A. Effect of a Neighborhood Health Center on Hospital Emergency Room Use. Medical Care. 1972; 10(3):240-47. [PubMed: 5041692]

National Archives Records about Community Action Program Grants and Grantees (NACAP). [Electronic Records]; Grantee Organization Masterfile, 7/1/1964-6/30/1971; Grantee Organization Master File, 7/1/1971-9/30/1981; Funded Program Account Master File, 7/1/1964-6/30/1971; Funded Program Account Master File, 7/1/1971-9/30/1977; Funded Program Account Master File, 10/1/1977-9/30/1981; Record Group 381. National Archives at College Park; College Park, MD:

National Archives Records about Federal Outlays (NAFO). [Electronic Records]; Record Group 381. National Archives at College Park; College Park, MD: 1967-1980. 
Newhouse, Joseph P.; the Insurance Experiment Group. Free for All? Lessons from the RAND Health Insurance Experiment. Cambridge, MA: Harvard University Press; 1993.

O'Connor, Patrick J.; Wagner, Edward H.; Strogatz, David S. Hypertension control in a rural community. An assessment of community-oriented primary care. Journal of Family Practice. 1990; 30(4):420-24. [PubMed: 2324694]

Office of Economic Opportunity. Comprehensive Neighborhood Health Services Proram Guidelines. Washington, DC: Health Services Office, Community Action Program; 1966.

Office of Economic Opportunity. The Neighborhood Health Center. Washington, DC: Office of Economic Opportunity; 1967.

Office of Economic Opportunity. The Comprehensive Neighborhood Health Service Program: Guidelines. Washington, DC: Health Services Office, Community Action Program; 1968.

Okada, Louise M.; Thomas, TH Wan. Impact of Community Health Centers and Medicaid on the Use of Health Services. Public Health Reports. 1980; 95(6):520-34. [PubMed: 7001529]

O’Malley, Ann S.; Forrest, Christopher B.; Politzer, Robert M.; Wulu, John T.; Shi, Leiyu. Health Center Trends, 1994-2001: What Do They Portend For The Federal Growth Initiative? Health Affairs. 2005; 24(2):465-72. [PubMed: 15757932]

Regional Economic Information System (REIS). Bureau of Economic Analysis, US Department of Commerce, CIESIN. 1969-1989. http://www.ciesin.org/datasets/reis/reis-home.html (accessed February 2009)

Ruggles, Steven; Alexander, J Trent; Genadek, Kate; Goeken, Ronald; Schroeder, Matthew B.; Sobek, Matthew. Integrated Public Use Microdata Series: Version 5.0 [Machine-readable database]. Minneapolis: University of Minnesota; 2010.

Rust, George; Baltrus, Peter; Ye, Jiali; Daniels, Elvan; Quarshie, Alexander; Boumbulian, Paul; Strothers, Harry. Presence of a Community Health Center and Uninsured Emergency Department Visit Rates in Rural Counties. Journal of Rural Health. 2009; 25(1):8-16. [PubMed: 19166556]

Sardell, Alice. Neighborhood Health Centers and Community-Based Care: Federal Policy from 1965 to 1982. Journal of Public Health Policy. 1983; 4(4):484-503. [PubMed: 6363451]

Sardell, Alice. The US Experiment in Social Medicine: The Community Health Center Program, 1965-1986. Pittsburgh: University of Pittsburgh Press; 1988.

Shea, Steven; Misra, Dawn; Ehrlich, Martin H.; Field, Leslie; Francis, Charles K. Predisposing Factors for Severe, Uncontrolled Hypertension in an Inner-City Minority Population. New England Journal of Medicine. 1992; 327(11):776-81. [PubMed: 1501654]

Shi, Leiyu; Macinko, James; Starfield, Barbara; Xu, Jiahong; Politzer, Robert. Primary Care, Income Inequality, and Stroke Mortality in the United States: A Longitudinal Analysis, 1985-1995. Stroke. 2003; 34(8):1958-64. [PubMed: 12843344]

Shi L, Macinko J, Starfield B, Xu J, Regan J, Politzer R, Wulu J. Primary care, infant mortality, and low birth weight in the states of the USA. Journal of Epidemiology and Community Health. 2004; 58(5):374-80. [PubMed: 15082734]

Shi, Leiyu; Stevens, Gregory D.; Wulu, John T., Jr; Politzer, Robert M.; Xu, Jiahong. America's Health Centers: Reducing Racial and Ethnic Disparities in Perinatal Care and Birth Outcomes. Health Services Research. 2004; 39(6):1881-1902. [PubMed: 15533192]

Simeonova, Emilia. Doctors, patients and the racial mortality gap. Journal of Health Economics. 2013; 32(5):895-908. [PubMed: 23933996]

Sox, Colin M.; Swartz, Katherine; Burnstin, Helen R.; Troyen, A Brennan. Insurance or a Regular Physician: Which is the Most Powerful Predictor of Health Care? American Journal of Public Health. 1998; 88(3):364-70. [PubMed: 9518965]

Special Health Revenue Sharing Act of 1975, Public Law 94-63, 89 Stat. 304, 42 U.S.C. 246.

Surveillance, Epidemiology, and End Results (SEER). Program Populations 1969-1988. National Cancer Institute, DCCPS, Surveillance Research Program, Cancer Statistics Branch; 2009. released November 2009

Ulmer, Cheryl; Lewis-Idema, Deborah; Von Worley, Ann; Rodgers, Judy; Berger, Lawrence R.; Darling, Elizabeth J.; Lefkowitz, Bonnie. Assessing Primary Care Content: Four Conditions Common in Community Health Center Practice. Journal of Ambulatory Care Management. 2000; 23(1):23-38. [PubMed: 11184893] 
United States Social Security Administration (US SSA), Office of Research and Statistics. Health insurance for the Aged and Disabled, 1966 and 1967. Washington, DC: 1969. Section 1.1: Reimbursement by State and County

United States Social Security Administration (US SSA), Office of Research and Statistics. Health insurance for the Aged and Disabled, 1968. Washington, DC: 1970. Section 1.1: Reimbursement by State and County

United States Social Security Administration (US SSA), Office of Research and Statistics. Health insurance for the Aged and Disabled, 1969. Washington, DC: 1971. Section 1.1: Reimbursement by State and County

United States Social Security Administration (US SSA), Office of Research and Statistics. Health insurance for the Aged and Disabled, 1970. Washington, DC: 1973. Section 1.1: Reimbursement by State and County

United States Social Security Administration (US SSA), Office of Research and Statistics. Health insurance for the Aged and Disabled, 1971. Washington, DC: 1973. Section 1.1: Reimbursement by State and County

United States Social Security Administration (US SSA), Office of Research and Statistics. Health insurance for the Aged and Disabled, 1972. Washington, DC: 1975. Section 1.1: Reimbursement by State and County

United States Social Security Administration (US SSA), Office of Research and Statistics. Health insurance for the Aged and Disabled, 1974 and 1975. Washington, DC: 1977. Section 1.1: Reimbursement by State and County

United States Health Care Financing Administration (US HFA), Office of Policy Planning, and Research. Medicare: Health Insurance for the Aged and Disabled, 1976. Washington, DC: 1978. Section 1.1: Reimbursement by State and County

United States Health Care Financing Administration (US HFA), Office of Policy Planning, and Research. Medicare: Health Insurance for the Aged and Disabled, 1977. Washington, DC: 1978. Section 1.1: Reimbursement by State and County

United States Health Care Financing Administration (US HFA), Office of Policy Planning, and Research. Medicare: Health Insurance for the Aged and Disabled, 1978 and 1979. Washington, DC: 1980. Section 1.1: Reimbursement by State and County

US Congress House. Tide of progress, 3rd annual report, Office of Economic Opportunity. 1967. 90th Cong., 1st sess. H. Doc. 397

US Department of Health and Human Services (US DHHS), Health Resources and Services Administration, Bureau of Primary Health Care. Health Centers: America's Primary Care Safety Net, Reflections on Success, 2002-2007. Rockville, MD: 2008. ftp://ftp.hrsa.gov/bphc/ HRSA_Health-CenterProgramReport.pdf

US Department of Health and Human Services (US DHHS), Health Resources and Services Administration, Bureau of Health Professions. Bureau of Health Professions Area Resource File, 1940-1990 [United States] [Computer file]. 2nd ICPSR release. Rockville, MD: U.S. Dept. of Health and Human Services, Office of Data Analysis and Management [producer]; Ann Arbor, MI: Inter-university Consortium for Political and Social Research [distributor]; 1994. 19911994

US Department of Health and Human Services (US DHHS), National Center for Health Statistics. Multiple Cause of Death, 1959-1988 [Computer file] ICPSR03895-v2. Hyattsville, MD: U.S. Dept. of Health and Human Services, National Center for Health Statistics [producer]; Ann Arbor, MI: 2007. 2001Inter-university Consortium for Political and Social Research [distributor]2007-05-29

US Department of Health and Human Services (US DHHS), National Center for Health Statistics. National Mortality Followback Survey, 1966-1968 [Computer file]. Washington, DC: U.S. Dept. of Health and Human Services, National Center for Health Statistics [producer]; Ann Arbor, MI: Inter-university Consortium for Political and Social Research [distributor]; 1986. 19681986

US Department of Health and Human Services (US DHHS), National Center for Health Statistics. National Health Examination Survey, Cycle I, 1959-1962: Demographic Data [Computer file]. Washington, DC: U.S. Dept. of Health and Human Services, National Center for Health Statistics [producer]; Ann Arbor, MI: Inter-university Consortium for Political and Social Research [distributor]; 1989a. 19771989 
US Department of Health and Human Services (US DHHS), National Center for Health Statistics. National Health Examination Survey, Cycle I, 1959-1962: Cardiovascular Findings [Computer file]. Washington, DC: U.S. Dept. of Health and Human Services, National Center for Health Statistics [producer]; Ann Arbor, MI: 1989b. 1977Inter-university Consortium for Political and Social Research [distributor] 1989

Veterans Administration Cooperative Study Group (VACG) on Antihypertensive Agents. Effects of Treatment on Morbidity in Hypertension: Results in Patients With Diastolic Blood Pressures Averaging 115 Through $129 \mathrm{~mm} \mathrm{Hg}$. Journal of the American Medical Association. 1967; 202(11):1028-34. [PubMed: 4862069]

Veterans Administration Cooperative Study Group (VACG) on Antihypertensive Agents. Effects of Treatment on Morbidity in Hypertension II: Results in Patients With Diastolic Blood Pressures Averaging 90 Through 114 mm Hg. Journal of the American Medical Association. 1970; 213(7): 1143-52. [PubMed: 4914579]

Viscusi, W Kip. Fatal Tradeoffs: Public and Private Responsibilities for Risk. New York: Oxford University Press; 1992.

Wheeler, Raymond. Health and Human Resources. New South. 1971; 26(4):2-16. [PubMed: 11632595]

Zwick, Daniel. Some Accomplishments and Findings of Neighborhood Health Centers. The Millbank Memorial Fund Quarterly. 1972; 50(4):387-420. 


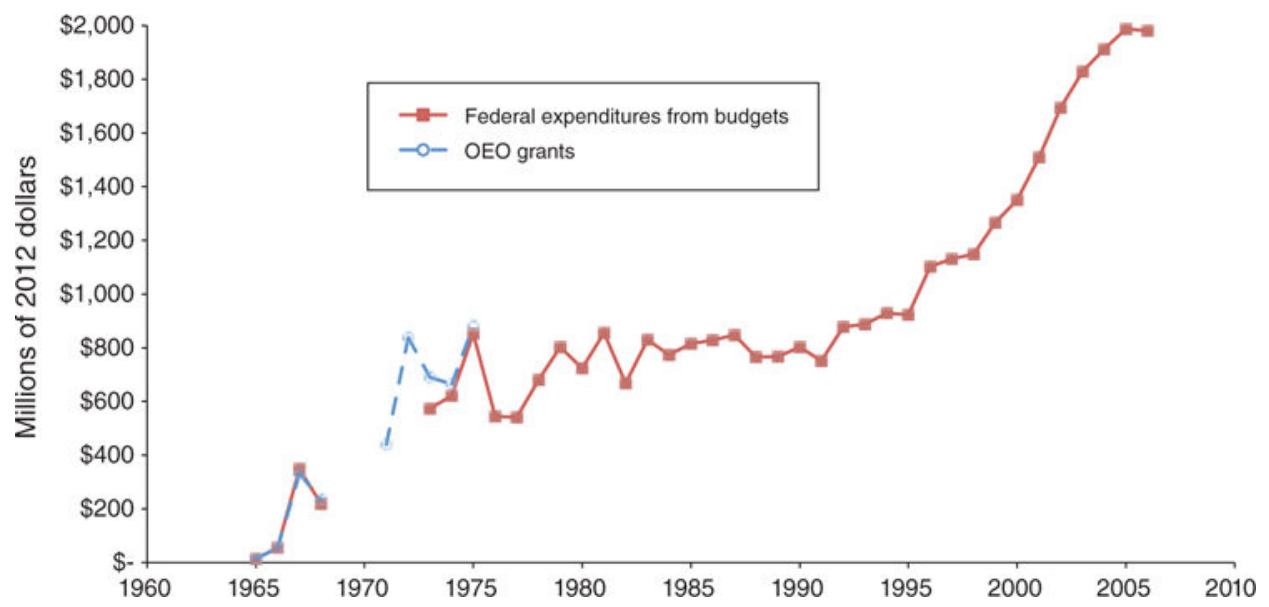

Figure 1.

Community Health Center Funding, 1965-2000

Notes: Federal expenditure data are expenditures for the Neighborhood or Community Health Center program. Differences between federal expenditures and state grants received may be due to double-counting of centers or funding spread over multiple years that is reported in one year only.

Sources: Information on OEO grants comes from the NACAP and NAFO files. Federal expenditures data are taken from line-items in the Budget of the United States Government and US Department of Health, Education, and Welfare. 
Panel A. AMR: all ages

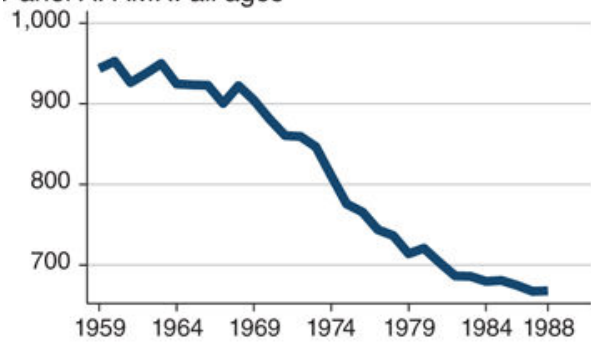

Panel C. AMR: children (1-19) and adults (20-49)

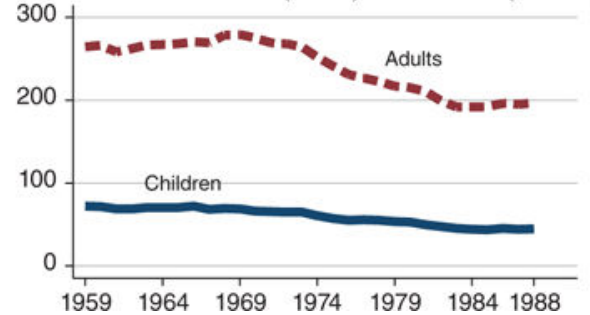

Panel B. Infant mortality rates

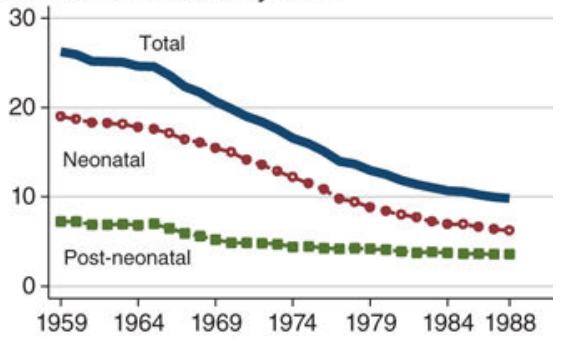

Panel D. AMR: older adults $(50+)$

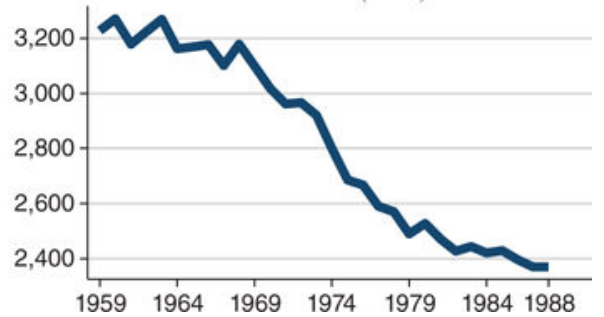

Figure 2.

All-Cause Mortality Rates by Age Group, 1959-1988

Sources: Vital Statistics Multiple-Cause of Death Files (US DHHS 2007), 1950 and 1960 population estimates (Haines and ICPSR 2005), and 1969 to 1988 population statistics (SEER 2009). 


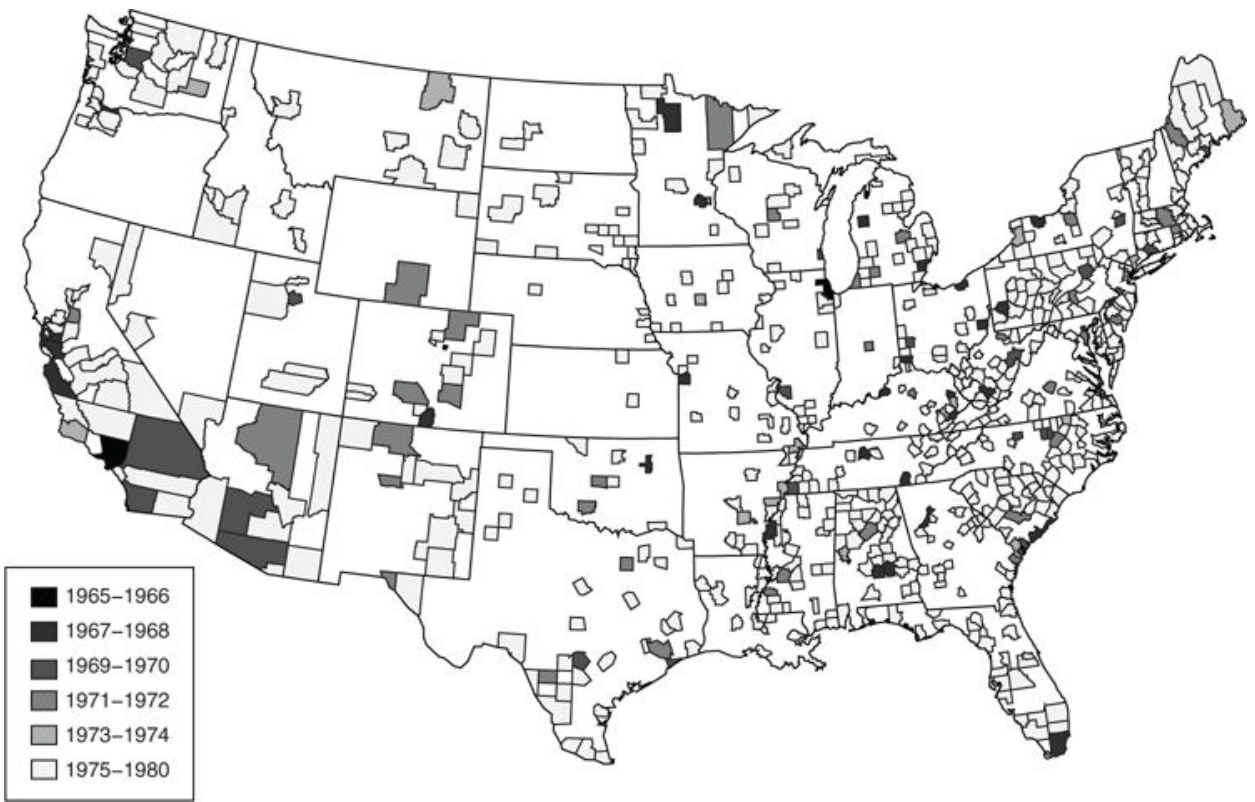

Figure 3.

Establishment of Community Health Centers by County of Service Delivery, 1965-1980 Note: Dates are the first year that a $\mathrm{CHC}$ was established in the county. Source: Information on CHCs drawn from NACAP and PHS reports. 

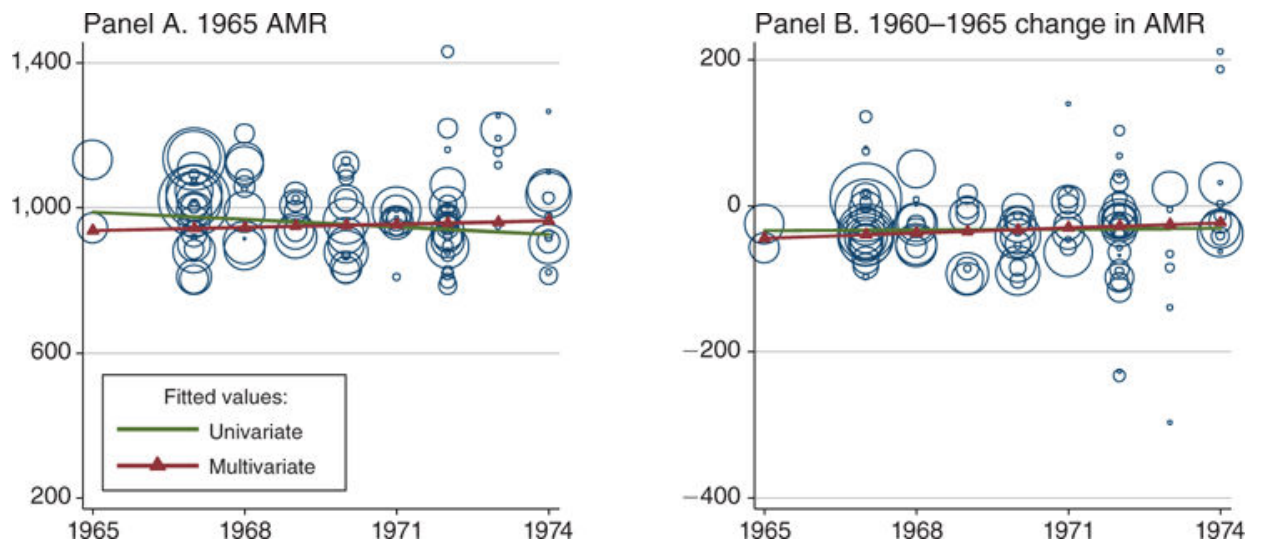

Figure 4.

Relationships between Community Health Center Initiation and Mortality Rates

Notes: AMR = Age adjusted mortality rate. The dependent variable refers to levels of our changes in age-adjusted mortality over all ages. Univariate fitted values are from regressions of the dependent variable on the year CHCs were established for the 114 treated counties in the estimation sample. The estimated univariate slopes are $-6.9(\mathrm{SE}=6.1)$ for panel $\mathrm{A}$, and 0.2 ( $\mathrm{SE}=1.4$ ) for panel B. Multivariate regressions follow Almond et al. (2011) and include the 1960 share of the county population that is urban, rural, between ages 0 and 4 , older than 64 , nonwhite, has more than 12 years of education, has less than 4 years of education, has family income less than $\$ 3,000$, has family income more than $\$ 10,000$; and the per capita number of physicians (see Table 1$)$. The estimated multivariate slopes are $2.9(\mathrm{SE}=2.7)$ for panel $\mathrm{A}$ and $2.3(\mathrm{SE}=1.7)$ for panel $\mathrm{B}$.

Source: See Figures 1 and 2. 


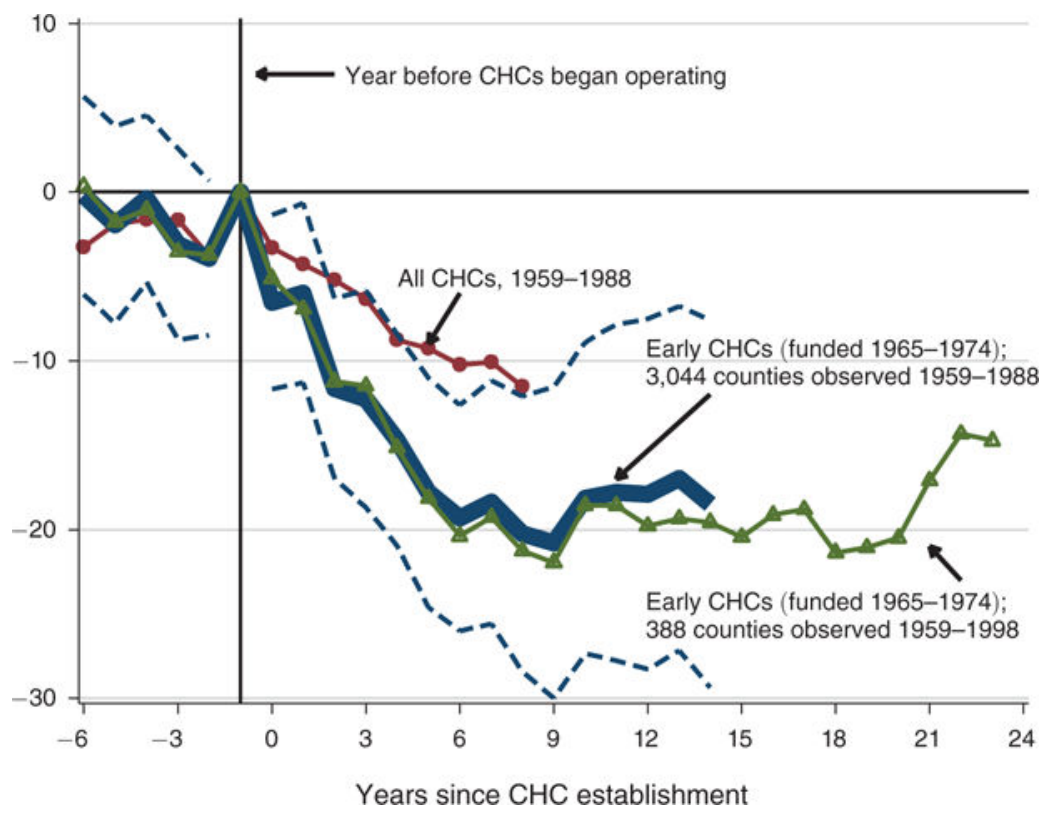

Figure 5.

The Relationship between Community Health Centers and Mortality Rates

Notes: The dependent variable is the age-adjusted mortality rate (AMR) per 100,000 residents. The coefficients are weighted least-squares estimates of $\pi$ and $\tau$ from our baseline specification of equation (1). Dashed lines are 9 percent confidence intervals for the models using the early CHCs (1965-1974) on the county sample observed 1959-1988 and are based on standard errors corrected for an arbitrary covariance structure at the county level.

Weights are the total county populations in 1960. See text for further model details. The year prior to the establishment of the $\mathrm{CHC}$ is omitted because $\mathrm{CHCs}$ were funded for the entirety of years 1-14 but only for part of year 0. Samples: 1959-1988: 3,044 US counties with valid data on 1960 characteristics (91,320 county-year observations). 1959-1988: 388 US counties that are identified in each year of vital statistics data $(15,520$ county-year observations).

Sources: Mortality rates constructed from the 1959-1988 Vital Statistics Multiple-cause of Death Files (US DHHS 2007), 1950 and 1960 population estimates (Haines and ICPSR 2005), and 1969-1988 population statistics (SEER 2009). Information on CHCs is drawn from NACAP and PHS reports. 


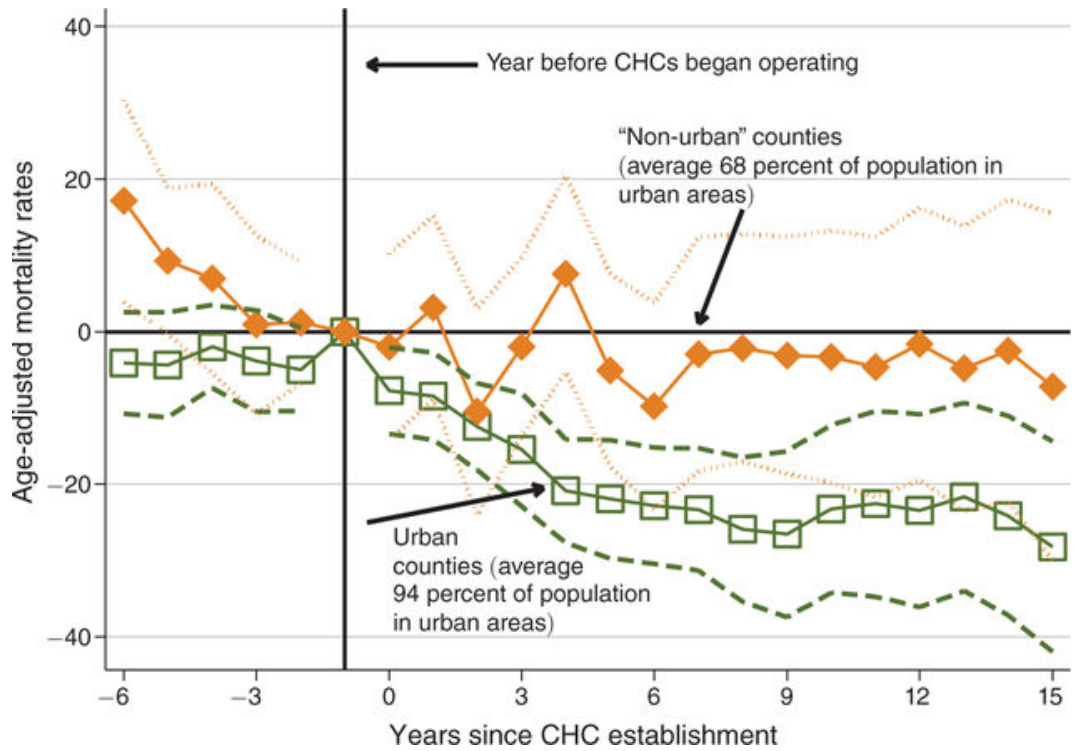

Figure 6.

Heterogeneity in the Relationship between Community Health Centers and Mortality Rates by Population Density

Notes: The coefficients are weighted, least-squares estimates of $\pi$ and $\tau$ from our baseline specification of equation (1) where the event-study dummies are estimated separately for areas with above (labeled "urban") and below (labeled "non-urban") the median 1960 urban share of the population among treated counties. See Figure 5 notes for details on the specification and sources. 
Panel A. Infant mortality rate

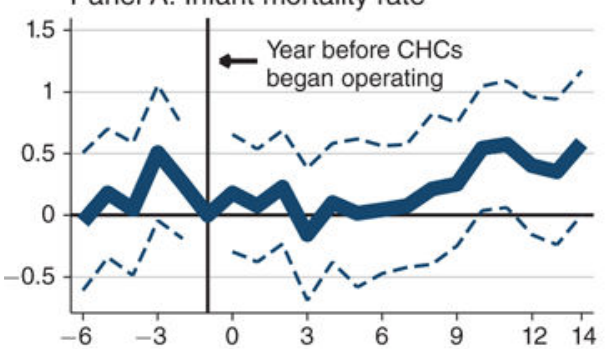

Panel C. AMR: adults (15-49)

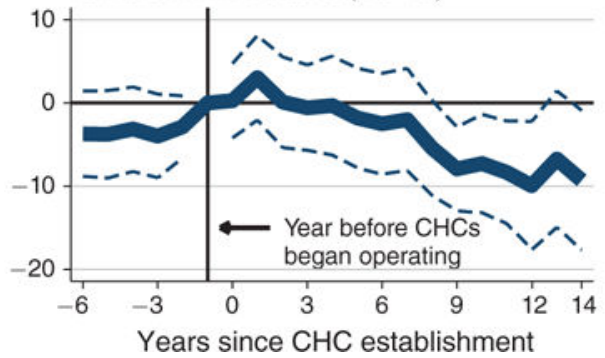

B. AMR: children (1-14)

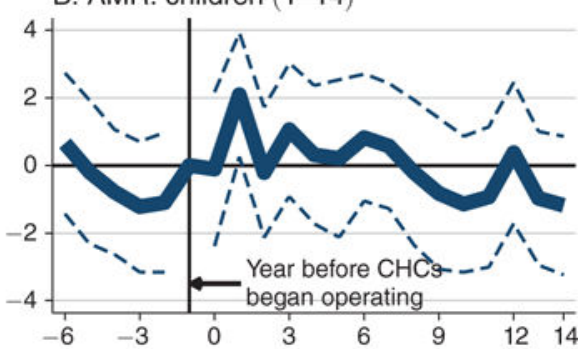

D. AMR: older adults $(50+)$

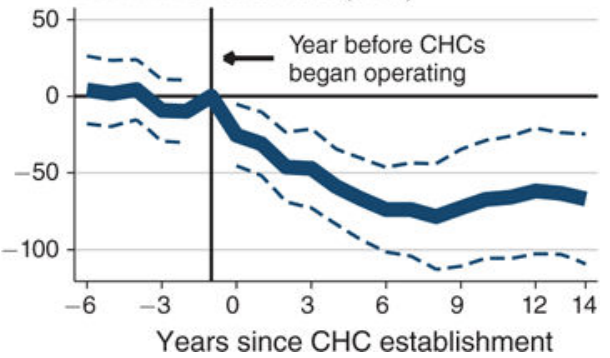

Figure 7.

The Relationship between Community Health Centers and Age-Group Mortality Rates

Notes: The dependent variable is the all-cause, age-adjusted mortality rate for the indicated age group. Infant mortality is measured per 1,000 live births and mortality rates for other groups are measured per 100,000 residents. Weights are the appropriate county populations in 1960. Infant sample: 2,982 counties with valid data on 1960 characteristics identified in both mortality and natality files (89,460 county-year observations). Mean of infant mortality rate in treated counties in $t-1: 21.4$ deaths per 1,000 live births. Non-infant sample: 3,044 US counties with valid data on 1960 characteristics (91,320 county-year observations). Mean of AMR in treated counties in $t-1$ for children is 64 ; for adults is 291 ; and for older adults is 3,213 (deaths per 100,000). See notes to Figure 5 for details. 

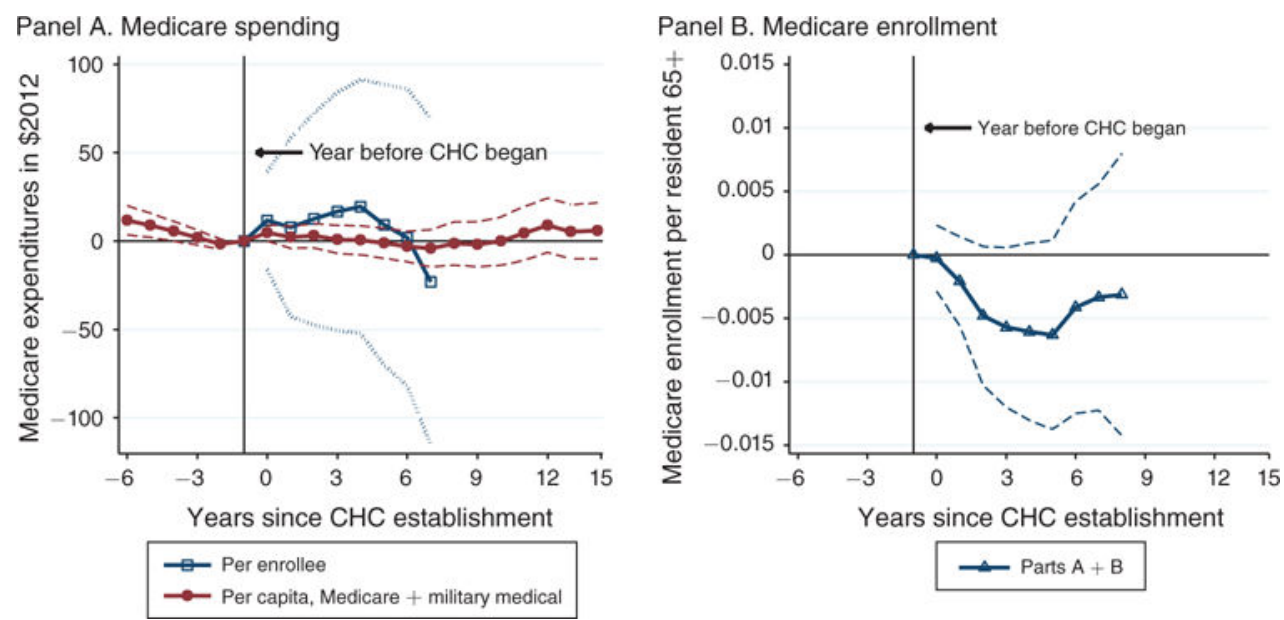

Figure 8.

Relationship between Community Health Centers and Medicare Utilization

Notes: The figure plots weighted least-squares estimates of $\pi$ and $\tau$ from our baseline specification of equation (1). The dependent variable in panel A is real (\$2012) Medicare spending per enrollee and in panel B it is the Medicare enrollment rates in parts A and B (enrollees divided by county population 65 and older). In treated counties in the year before CHC establishment, the sample means are 0.97 and 0.93 for enrollment in parts $\mathrm{A}$ and $\mathrm{B}$, $\$ 1,089.83$ for per-enrollee spending on part A, and $\$ 429.22$ for B. 1973 is missing and is linearly interpolated. Data from July 1966 through December 1967 is allocated to calendar years 1966 and 1967 in proportion to the number of months (1/3 and 2/3).

Sources: County level Medicare (US SSA 1969-1977; US HFA 1978-1980) and the Area Resource File (US DHHS 1994). Data on Medicare and military medical expenditures (panel A) were shared by Almond, Hoynes, and Schanzenbach (2011) 
Panel A. Share of counties receiving a federal grant, by program
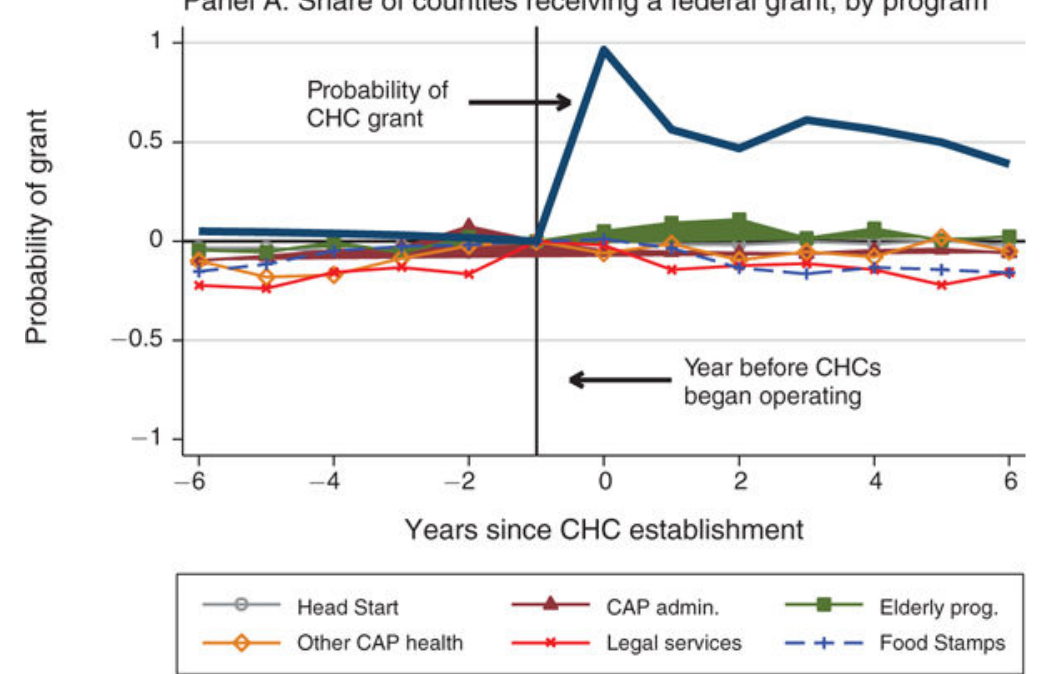

Panel B. Number of hospitals or hospital beds per capita

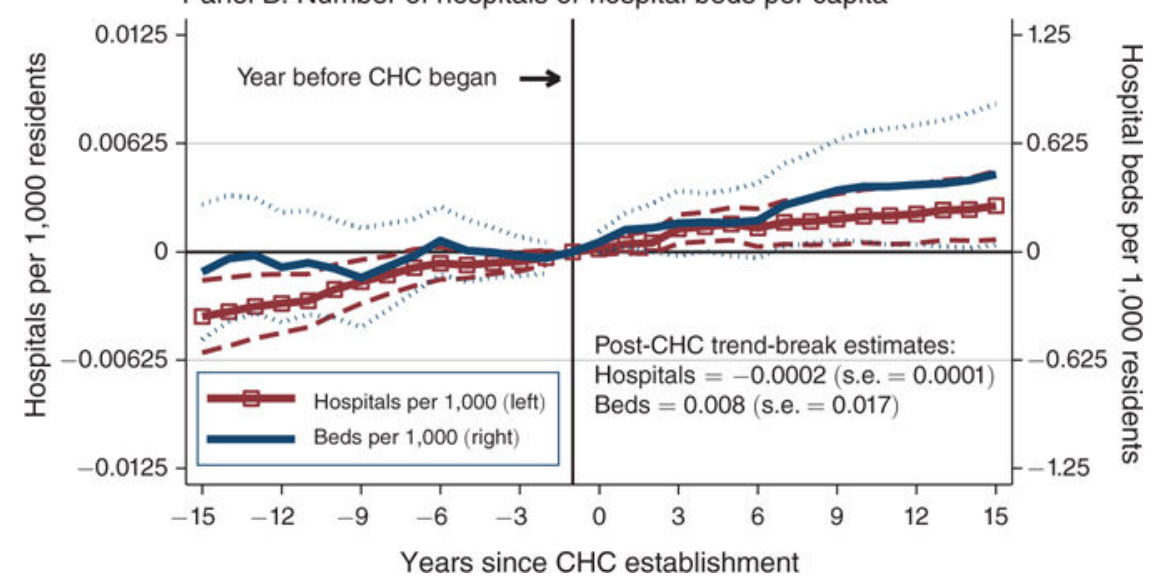

Figure 9.

The Relationship between Community Health Centers, Other Federal Program Grants, and Hospital Capacity

Notes: The figure plots weighted least-squares estimates of $\pi$ and $\tau$ from our baseline specification of equation (1). In panel A, the dependent variable is equal to 1 if the county received any federal grant for the indicated program in a given year. In the case of Food Stamps, the dependent variable is equal to 1 at the date of implementation. In panel B, the dependent variables are hospitals per thousand residents (left vertical axis) and beds per thousand residents (right vertical axis). The sample excludes mental institutions, tuberculosis sanatoriums, military hospitals, and correctional hospitals. The sample means are 0.025 for hospitals per capita and 6.18 for beds per capita in treated counties in the year before CHC establishment. We omit REIS variables from panel B specifications (because they are not measured before 1959) and the AHA variables (because they are the key lefthand side variables). Data for 1954, 1977, and 1979 are missing and linearly interpolated. Trend-break estimates come from a model which contains an event-time variable, an interaction between event-time and post-treatment, and a dummy for post-treatment. See Figure 5 notes for details on the specification and sample. 
Sources: NACAP, NAFO, PHS reports (see online Appendix A); Almond, Hoynes, and Schanzenbach (2011) for the Food Stamp data, 1948 to 1975 AHA Surveys (provided by Amy Finkelstein), and the 1972 to 1990 AHA Surveys (provided by the NBER). 


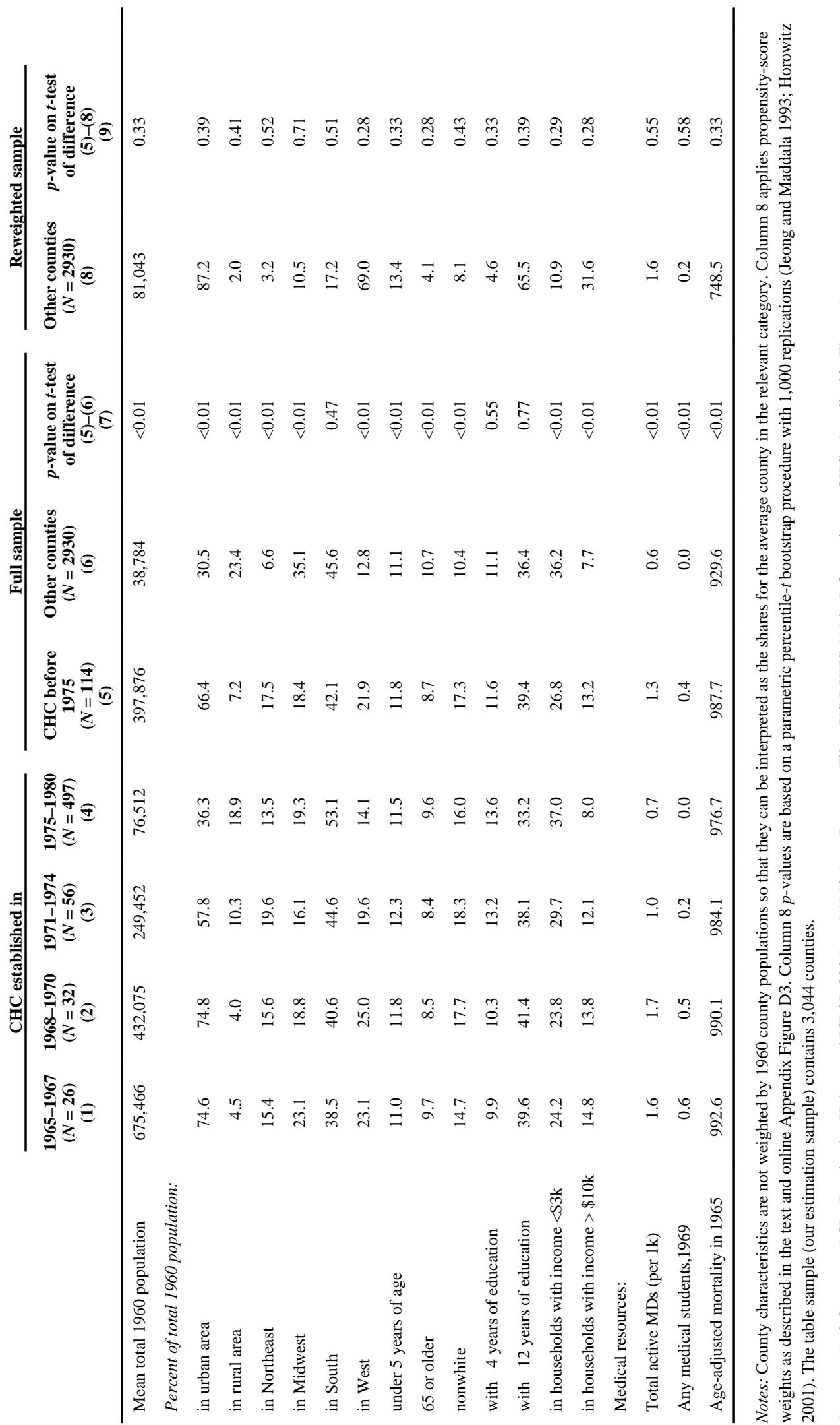


Table 2

Robustness Checks on the Relationship between Community Health Centers and All-Cause Mortality Rates

\begin{tabular}{|c|c|c|c|c|}
\hline & (1) & (2) & (3) & (4) \\
\hline \multicolumn{5}{|c|}{ Panel A. Age-adjusted mortality, all ages } \\
\hline Mean at $t^{*}=-1$ & & & 929.3 & \\
\hline Years -6 to -2 & $\begin{array}{l}0.03 \\
{[2.8]}\end{array}$ & $\begin{array}{l}-2.0 \\
{[2.1]}\end{array}$ & $\begin{array}{l}-2.7 \\
{[2.0]}\end{array}$ & $\begin{array}{c}1.5 \\
{[3.2]}\end{array}$ \\
\hline Years 0 to 4 & $\begin{array}{l}-5.6 \\
{[3.5]}\end{array}$ & $\begin{array}{c}-10.1 \\
{[2.3]}\end{array}$ & $\begin{array}{l}-9.0 \\
{[2.4]}\end{array}$ & $\begin{array}{l}-8.6 \\
{[2.6]}\end{array}$ \\
\hline Years 5 to 9 & $\begin{array}{r}-12.1 \\
{[4.6]}\end{array}$ & $\begin{array}{r}-18.9 \\
{[3.5]}\end{array}$ & $\begin{array}{r}-15.7 \\
{[3.5]}\end{array}$ & $\begin{array}{r}-13.9 \\
{[3.7]}\end{array}$ \\
\hline Years 10 to 14 & $\begin{array}{c}-9.4 \\
{[5.6]}\end{array}$ & $\begin{array}{r}-17.5 \\
{[4.8]}\end{array}$ & $\begin{array}{r}-11.8 \\
{[4.6]}\end{array}$ & $\begin{array}{r}-18.4 \\
{[4.7]}\end{array}$ \\
\hline$R^{2}$ & 0.82 & 0.85 & 0.87 & 0.96 \\
\hline \multicolumn{5}{|c|}{ Panel B. Age-adjusted mortality, 50 years and older } \\
\hline Mean at $t^{*}=-1$ & & & 3,213 & \\
\hline Years -6 to -2 & $\begin{array}{c}10.6 \\
{[10.2]}\end{array}$ & $\begin{array}{l}-2.0 \\
{[8.0]}\end{array}$ & $\begin{array}{l}-3.3 \\
{[8.1]}\end{array}$ & $\begin{array}{c}5.3 \\
{[11.1]}\end{array}$ \\
\hline Years 0 to 4 & $\begin{array}{l}-29.5 \\
{[13.7]}\end{array}$ & $\begin{array}{c}-41.1 \\
{[9.6]}\end{array}$ & $\begin{array}{r}-38.2 \\
{[8.9]}\end{array}$ & $\begin{array}{l}-30.5 \\
{[11.3]}\end{array}$ \\
\hline Years 5 to 9 & $\begin{array}{c}-58.4 \\
{[17.3]}\end{array}$ & $\begin{array}{l}-72.0 \\
{[14.8]}\end{array}$ & $\begin{array}{c}-62.3 \\
{[11.7]}\end{array}$ & $\begin{array}{l}-49.1 \\
{[15.7]}\end{array}$ \\
\hline Years 10 to 14 & $\begin{array}{l}-48.7 \\
{[21.1]}\end{array}$ & $\begin{array}{l}-64.1 \\
{[19.3]}\end{array}$ & $\begin{array}{l}-46.9 \\
{[15.3]}\end{array}$ & $\begin{array}{l}-61.0 \\
{[18.6]}\end{array}$ \\
\hline$R^{2}$ & 0.78 & 0.80 & 0.84 & 0.96 \\
\hline Covariates & $\mathrm{C}, \mathrm{U}-\mathrm{Y}$ & $\begin{array}{c}\text { C, U-Y, S-Y, } \\
\text { R, D.Year }\end{array}$ & $\begin{array}{c}\text { C, U-Y, S-Y, } \\
\text { R, C·Year }\end{array}$ & $\begin{array}{l}\text { C, U-Y, S-Y } \\
\text { R, P-weights }\end{array}$ \\
\hline
\end{tabular}

Notes: Models presented are weighted least-squares estimates of equation (1) using event-year categories. C: county fixed effects; U-Y: urban by year fixed effects; S-Y: state-by-year fixed effects; R: annual, county-level covariates; D.Year: 1960 characteristics interacted with linear time trends; C.Year: county-specific linear time trends; P-weights: uses an estimate of the propensity of receiving a CHC to reweight untreated counties. See text for more details. Weights are the relevant county populations in 1960. See notes to Figure 5 and 6 for details on sample and sources. 


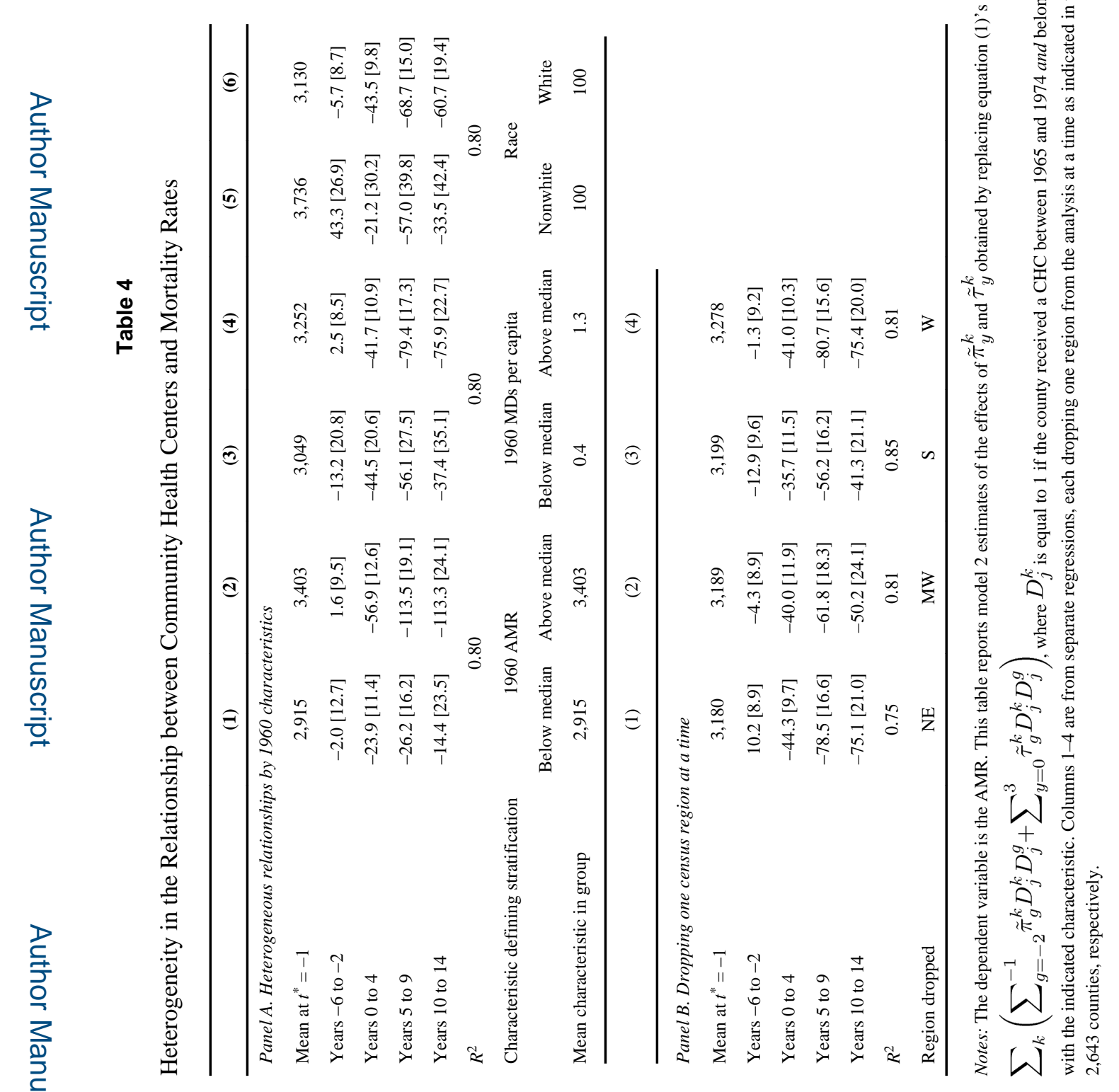


Table 5

The Relationship between Community Health Centers and Primary Care Use among Older Adults by Poverty Status

\begin{tabular}{|c|c|c|c|c|}
\hline & $\begin{array}{c}\text { Regular source of care } \\
\text { (1) }\end{array}$ & $\begin{array}{r}\text { Scheduled visits + } \\
\text { hospital admits (2) }\end{array}$ & $\begin{array}{c}\text { Saw physician last } \\
\text { year (3) }\end{array}$ & $\begin{array}{l}\text { Any out-of-pocket } \\
\text { prescription drug } \\
\text { expenditures (4) }\end{array}$ \\
\hline \multicolumn{5}{|c|}{ Panel A. Household income less than 100 percent of poverty line } \\
\hline $\begin{array}{l}\text { Mean dependent variable in } \\
1963 \text { in treated PSUs }\end{array}$ & 0.76 & 6.96 & 0.66 & 0.56 \\
\hline $\mathrm{CHC} \times 1970$ & $0.18[0.06]$ & $2.66[3.87]$ & $-0.03[0.09]$ & $-0.18[0.11]$ \\
\hline Observations & 949 & 949 & 949 & 949 \\
\hline$R^{2}$ & 0.23 & 0.23 & 0.20 & 0.21 \\
\hline \multicolumn{5}{|c|}{ Panel B. Household income between 100 and 299 percent of the poverty line } \\
\hline $\begin{array}{l}\text { Mean dependent variable in } \\
1963 \text { in treated PSUs }\end{array}$ & 0.86 & 8.85 & 0.69 & 0.53 \\
\hline $\mathrm{CHC} \times 1970$ & $-0.06[0.06$ & $-0.91[1.53]$ & $-0.05[0.07]$ & $-0.09[0.08]$ \\
\hline Observations & 2,073 & 2,073 & 2,073 & 2,073 \\
\hline$R^{2}$ & 0.10 & 0.09 & 0.10 & 0.10 \\
\hline \multicolumn{5}{|c|}{ Panel C. Household income over 300 percent of the poverty line } \\
\hline $\begin{array}{l}\text { Mean dependent variable in } \\
1963 \text { in treated PSUs }\end{array}$ & 0.89 & 7.53 & 0.71 & 0.56 \\
\hline $\mathrm{CHC} \times 1970$ & $-0.04[0.04]$ & $-0.32[2.02]$ & $0.03[0.06]$ & $0.02[0.07]$ \\
\hline Observations & 1,218 & 1,218 & 1,218 & 1,218 \\
\hline$R^{2}$ & 0.12 & 0.12 & 0.13 & 0.14 \\
\hline $\begin{array}{l}\mathrm{H}_{0} \text { : Coef. in panel } \mathrm{C}=\text { coef. in } \\
\text { panel } \mathrm{A}(p \text {-value })\end{array}$ & 0.00 & 0.49 & 0.60 & 0.10 \\
\hline
\end{tabular}

Notes: See text for details on the dependent variables. "CHC $\times 1970$ " corresponds to the interaction of the dummy variable for 1970 and the dummy variable for receiving a CHC before 1970. Mean DV gives the mean of the dependent variable in treated PSUs in 1963. The sample includes respondents ages 50 and older and the estimates are weighted by the final survey weights (see online data Appendix for a discussion of the SHSUE weights). See online Appendix Table F5 for unweighted estimates.

Sources: Survey of Health Services Utilization and Expenditure 1963 and 1970 (Center for Health Administration Studies/National Opinion Research Center 1981, 1988). 